\title{
Cytoskeleton and Golgi-apparatus interactions: a two-way road of function and structure
}

This article was published in the following Dove Press journal:

Cell Health and Cytoskeleton

22 January 2015

Number of times this article has been viewed

\author{
Gustavo Egea' \\ Carla Serra-Peinado' \\ María P Gavilan² \\ Rosa M Rios ${ }^{2}$ \\ 'Departament de Biologia Cel.lular, \\ Immulogia i Neurociències, \\ Facultat de Medicina and Institut \\ d'Investigacions Biomèdiques August \\ $\mathrm{Pi}$ i Sunyer (IDIBAPS), Universitat \\ de Barcelona, Barcelona, Spain; \\ Departamento de Señalización \\ Celular, CSIC-Centro Andaluz de \\ Biomedicina y Medicina Regenerativa \\ (CABIMER), Seville, Spain
}

\begin{abstract}
The Golgi apparatus is the result of a complex and dynamic interaction between a large variety of molecules that determine its architecture, protein and lipid transports, and those that integrate signals from outside and inside the cell. The cytoskeleton facilitates the functional integration of all these processes. Association and coordination between microtubules and actin filaments, as well as their respective binding and regulatory proteins, are clearly necessary for Golgi structure and function. Protein sorting, membrane fission and fusion, and the motion of Golgi-derived transport carriers are all affected by both cytoskeleton elements.
\end{abstract}

Keywords: cytoskeleton, Golgi apparatus, membrane trafficking, secretory pathway, actin, microtubules

\section{Introduction}

The Golgi apparatus (GA) is the central organelle of the eukaryotic secretory pathway. While its basic function is highly conserved, the GA varies greatly in shape and number from one organism to another. In the simplest organisms, like budding yeast Saccharomyces cerevisiae, the organelle takes the form of dispersed cisternae or isolated tubular networks. ${ }^{1,2}$ Unicellular green alga $^{3}$ and many protozoa like Toxoplasma gondii ${ }^{4}$ and Trypanosoma bruce $^{5,6}$ contain a single pile of flattened cisternae aligned in parallel that is referred to as a dictyosome or Golgi stack. ${ }^{7}$ In fungi, ${ }^{8,9}$ plants, ${ }^{10,11}$ or Drosophila, ${ }^{12}$ many separate Golgi stacks are dispersed throughout the cytoplasm. In all these cases, each Golgi stack is associated with a single endoplasmic reticulum (ER) exit site, forming a secretory unit. In unpolarized nondividing mammalian cells, Golgi membranes are organized as a single-copy, ribbon-like shape and closely associated with the centrosome, which is usually located near the nucleus at the cell center. ${ }^{13,14}$ These cells display a radial microtubule (MT) array, with plus-ends facing toward the cell cortex and minus-ends anchored at the centrosome (Figure 1A). Once positioned near the centrosome, Golgi membranes are linked laterally to form the ribbon-like membrane network, after which the Golgi ribbon may be directly anchored to the centrosome. ${ }^{15-17}$ This organization is lost during cell division (mitosis), where a single Golgi ribbon first unlinks into individual stacks, which further undergo unstacking and vesiculation. These mitotic Golgi membranes are then partitioned between the two daughter cells, where they reassemble in a single Golgi ribbon after cytokinesis. ${ }^{18}$ The remodeling of the MT cytoskeleton causes a large reorganization of the GA. ${ }^{19-22}$ The cytoskeleton imposes the localization of the GA and largely participates in Golgi structure, cargo segregation at the trans-Golgi network (TGN), and subsequent production of transport 
A

C

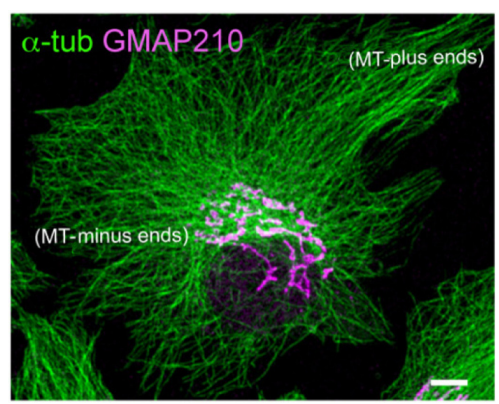

B
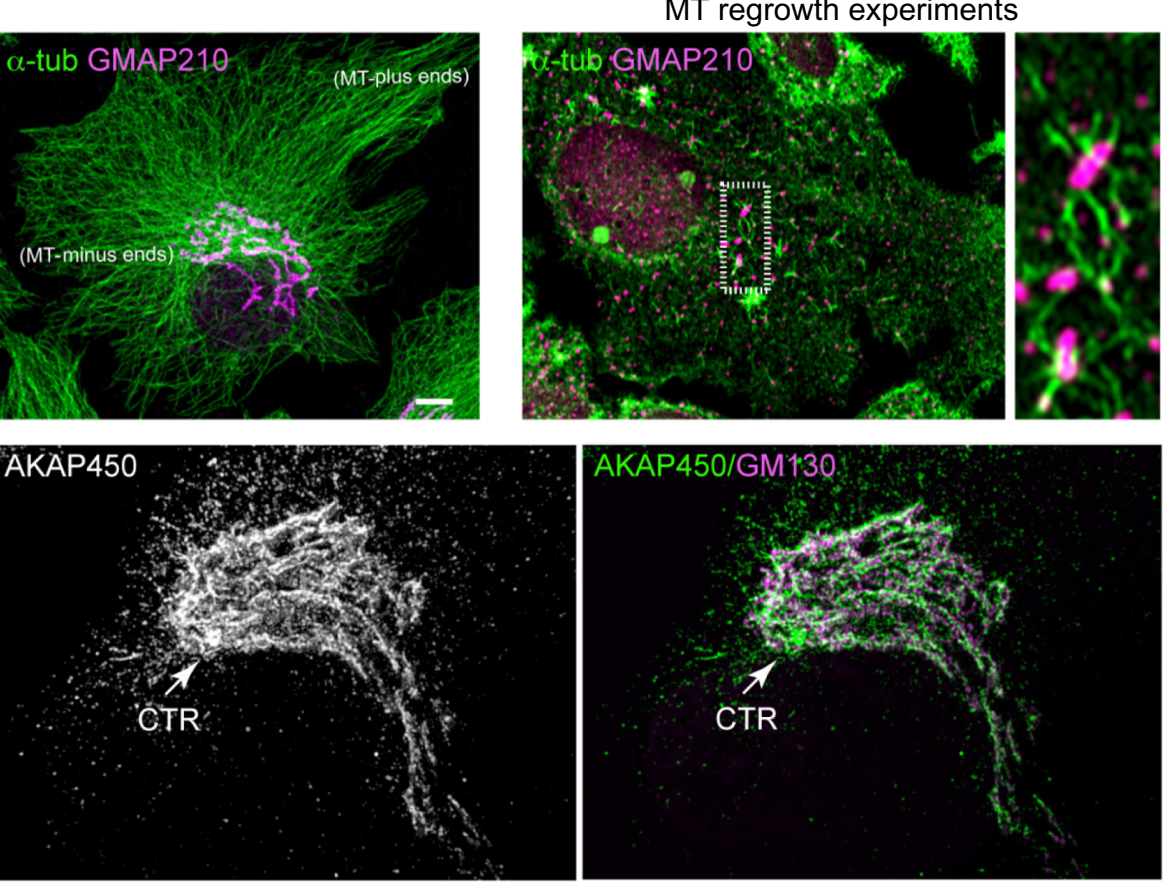

Figure I Microtubule-Golgi interaction.

Notes: (A) Immunofluorescence confocal image of RPE-I cells double labeled for $\gamma$-tubulin (green) and the Golgi protein GMAP2I0 (magenta). Note the characteristic ribbon-like shape of the Golgi apparatus and its position close to the nucleus and minus-ends of microtubules (MTs). (B) MT-regrowth experiments after nocodazole treatment in RPE-I. Shortly after drug washout, MTs can be seen growing from dispersed Golgi elements. $\alpha$-Tubulin is in green and GMAP2I 0 in magenta. Enlarged image of the outlined area is shown at right. (C) RPE-I cells stained for AKAP450 (green) and GMI30 (magenta) and visualized using an OMX superresolution microscope. Single labeling for AKAP450 is shown at left. White arrows indicate the centrosome (CTR). Bars, $10 \mu \mathrm{m}$.

carriers (vesicles and/or tubules). ${ }^{17,23-26}$ Which of these two cytoskeletal networks, MTs or actin filaments, is more critical for defining these properties depends on the cellular system. ${ }^{17,23-26}$ In the following sections, we provide a general overview of the structural and functional consequences of the coupling between these two cytoskeletal elements and the GA. The interaction between the GA and intermediate filaments is poorly documented and not reviewed here, but has been in previous reports. ${ }^{24,27}$

\section{Microtubules in the structure and dynamics of the Golgi apparatus} Structural relationship between the Golgi apparatus and microtubules

The essential role of the MT cytoskeleton in ensuring both the integrity of the GA as a single organelle and its pericentrosomal positioning has been acknowledged for a long time. ${ }^{28}$ Both features, integrity and positioning, are lost when MT depolymerization is induced by such drugs as nocodazole (NZ). In the absence of MTs, the Golgi-ribbon fragments give rise to discrete Golgi elements, which appear dispersed throughout the cytoplasm. ${ }^{28,29}$ The recent discovery that MT nucleation occurs not only at the centrosome but also at the GA in many cell types has substantially changed the concept of the relationship between the GA and MTs. It is now widely accepted that centrosome-nucleated MTs are responsible for GA pericentrosomal positioning, whereas Golgi-derived MTs are required for ensuring the structural integrity of the Golgi ribbon. ${ }^{17,30}$

In the last decade, advances in microscope technology have boosted our knowledge of MT dynamics and their relationship with the GA. Three-dimensional electron microscopy analysis allowed the modeling of individual MTs and analysis of their relationship with cisternae in situ. Interestingly, MTs were found to run parallel to the first cis-cisterna of Golgi stacks over long distances. MTs also cross Golgi stacks at multiple points via noncompact regions and cisternal openings. ${ }^{31}$ Time-lapse microscopy studies have revealed that in spite of GA's highly dynamic nature, global arrangement of the GA near the centrosome is relatively stable. Thin membrane tubules constantly form and detach from the lateral portions of almost stationary Golgi stacks. ${ }^{32-34}$ After extending from the GA, some tubules break off and move along MTs toward the ER, where they collapse, thus delivering Golgi proteins to the ER. ${ }^{35}$ Translocation of 
transport intermediates from the ER to the GA also depends on MTs. In the absence of MTs, Golgi proteins recycle back to the ER. Then, they are exported into pre-Golgi intermediates that fail to move to the pericentrosomal region. Over long periods of time, these membrane elements organize themselves as stacks of cisternae and become fully competent for general secretion. ${ }^{29,36}$ In a recent study, Tängemo et al employed laser nanosurgery to eliminate both Golgi complexes and centrosomes from living cells, and then they followed the de novo biogenesis of the GA. ${ }^{37}$ By using time-lapse and correlative electron microscopy, they found that stacked and transport-competent Golgi stacks could be formed under these conditions. Overall, these studies support that the capacity to organize membranes as Golgi stacks is an intrinsic property of ER-derived membranes. This step does not require MTs. However, the fusion of stacks into a single organelle located at the cell center around the centrosome is an MT-dependent process.

\section{Microtubule motor proteins at the Golgi apparatus}

A complete understanding of the mechanisms by which MTs influence the Golgi structure requires an understanding of how they contribute to membrane trafficking to and from the GA. Newly synthesized proteins and lipids at the ER are packed in transport carriers that move from peripherally located ER exit sites to the GA at the cell center. This anterograde transport occurs along MTs in a directional manner: transport carriers associate with MT plus-ends at the cell periphery and travel toward the minus-ends, where they fuse with the GA. This movement is powered by cytoplasmic dynein 1, which is the main minus-end-directed MT motor in eukaryotic cells. ${ }^{38-41}$ The opposite movement, from the GA toward the ER, was reported to involve plus-enddirected molecular motors, such as kinesin 1 (KIF5B) and kinesin $2 .{ }^{42,43}$ However, recent data point to a more complex scenario. By combining ribonucleic acid interference and automated image analysis followed by biochemical analysis, the role of different dynein subunits, and of kinesin 1 and 2 in membrane trafficking from the ER to the GA was examined. ${ }^{44,45}$ They found that almost all known subunits of the cytoplasmic dynein 1 complex were required to maintain the Golgi structure. More specifically, a particular subset of dynein 1 containing light intermediate chain 1 appeared to be critical for ER-to-Golgi trafficking. Depletion of this subset did mimic a direct block of ER export. Intriguingly, knockdown of either kinesin 1 (KIF5B) or kinesin 2 caused an increase in the run length of membrane carriers in vivo, suggesting that these motors can actually act as brakes on anterograde motility. ${ }^{45}$ These data strongly support a direct role of kinesins in ER-to-Golgi transport, acting as negative regulators of this membrane pathway. This activity probably occurs through opposing the minus-end-directed force of dynein. ${ }^{45}$

Dynein and kinesins share structural similarities. They consist of two functional parts: a motor domain that moves along MTs by converting chemical energy (derived from adenosine triphosphate [ATP] hydrolysis) into directed motion, and a tail domain that mediates cargo interactions either directly or by specific accessory proteins. ${ }^{46}$ How these motors are targeted to specific subcellular sites or how they bind their cargoes remains unclear. A candidate to mediate the interaction between dynein and membranes is dynactin, a multisubunit protein required for proper localization and activation of the molecular motor. Dynactin complex consists of eleven subunits, ${ }^{47,48}$ among which the Arp1 filament p150 Glued and p50/dynamitin are the best known. P150 Glued is a coiled-coil dimeric protein that in addition to dynein binds both the Arp1 filament and MTs. On the other hand, p50/ dynamitin plays an essential role in maintaining dynactin complex integrity. ${ }^{48}$ Expression of either a dominant negative version of $\mathrm{p} 150^{\text {Glued }}$ or overexpression of $\mathrm{p} 50 /$ dynamitin leads to fragmentation and dispersion of the GA. ${ }^{49,50}$ Under these conditions, trafficking of transport carriers between the ER and the GA is inhibited, as occurs in NZ-treated cells. ${ }^{32}$ It has been suggested that binding of dynactin to transport carriers facilitates both proper formation of carriers and their motion to the GA. ${ }^{51}$ This interaction is mediated by the $\mathrm{p} 150^{\text {Glued }}$ subunit of dynactin complex and Sec23p, a component of the COPII complex at the ER surface. Furthermore, the p150 Glued subunit of dynactin also interacts with kinesin 2 through its nonmotor subunit KAP3.$^{52}$ Downregulation of KAP3 blocks the retrograde trafficking pathway from the GA to the ER and induces disorganization of Golgi membranes. ${ }^{42}$ In summary, both kinesin 2 and dynein appear to bind the same dynactin subunit, suggesting a role for dynactin in regulating opposing motor activities and their processivity. Supporting this idea, both dynein and kinesin have been detected at the same membrane structures. ${ }^{52-56}$

The small guanosine triphosphatase (GTPase) Rab6 was also reported to play a major role in regulating membrane trafficking by recruiting MT motors to membranes. ${ }^{57-59}$ It is known that members of the Rab6 family participate in some steps of MT-dependent vesicle transport from the TGN. When activated, Rab6 recruits the protein bicaudal D, which in turn recruits dynein-dynactin complexes to Rab6-positive 
membranes, including Golgi elements. ${ }^{57-59}$ It was suggested that these complexes might form part of a recycling pathway from the TGN back to the ER. ${ }^{60}$ Other studies, however, pointed to the plasma membrane as the main target for the fusion of Rab6-containing vesicles. In this scenario, Rab6 would play a role in the constitutive secretory pathway by regulating both vesicle transport and targeting. ${ }^{61}$ Supporting this hypothesis, bicaudal D1/2 was shown to interact with the plus-end-directed motor kinesin 1 . Therefore, complex interactions involving dynein-dynactin, kinesin 1, Rab6, and bicaudal D1/2 appear to be required for Rab6-containing vesicles motion and targeting. ${ }^{59,61,62}$ Altogether these data suggest that in order to ensure proper directionality of membrane elements, recruitment and coordination of MT motor activities should be finely regulated. Defining and integrating the specific contribution of each of these mechanisms to the overall regulation of Golgi dynamics deserve further investigation. $^{47}$

\section{Golgins and microtubules at the Golgi apparatus}

While it is clear that the minus-end-directed motor dynein is the main factor responsible for inward movement of Golgi membranes that results in its characteristic position near the centrosome, other nonmotor proteins appear to be important players in this process also. The best studied are golgin-160 and GMAP210. ${ }^{14,63,64}$ Both of them are peripheral homodimeric coiled-coil proteins localized primarily at cis-Golgi cisternae. Depletion of each of them blocks Golgi positioning and yields dispersed in motile ministacks. Dispersed Golgi stacks in golgin-160- or GMAP210-depleted cells are competent for general protein transport to the cell surface, excluding an essential role for these proteins in membrane trafficking. ${ }^{63,64}$

Golgin-160 has been recently identified as the membrane receptor for dynein at the cis-Golgi. ${ }^{65}$ It directly binds the dynein intermediate chain through a C-terminal coiled-coil segment in an Arf1-GTP-dependent manner. Golgin-160dependent dynein recruitment was shown to be required for inward tracking movements of the Golgi membranes. ${ }^{65}$ Once Golgi elements have reached the cell center, active anchoring or tethering to the centrosome might further maintain their pericentrosomal position. GMAP210 is a good candidate to carry out this activity, as when targeted to mitochondria, it induces their clustering around the centrosome. ${ }^{63,64}$ GMAP210 has been shown to bind MT minus-ends and $\gamma$-tubulin. ${ }^{15}$ GMAP210 has at least two membrane-targeting motifs located at the ends of the protein, both of which are required to ensure its proper cis-Golgi localization and function. ${ }^{66,67}$ The N-terminus of GMAP210 contains an amphipathic lipid-packing sensor motif, a sequence that has been reported to bind lipids and to act as a curvature sensor in vitro. ${ }^{66,68}$ At the C-terminus, GMAP210 contains a GRIPrelated ARF binding motif (it binds to membranes containing ARF1-GTP) that has been proposed to mediate ARF1dependent recruitment to Golgi cisternae. ${ }^{69}$ Interestingly, when ectopically expressed, the N-terminal binding motif is concentrated in the periphery of Golgi elements and between Golgi stacks, whereas the C-terminal domain appears uniformly distributed in the cis-cisternae of the GA. It has been proposed that by anchoring the surface of cisternae via its $\mathrm{C}$-terminus and projecting its distal $\mathrm{N}$-terminus to bind the rims or to stabilize tubular structures connecting neighboring cis-cisternae, GMAP210 would participate in homotypic fusion of $c$ is-cisternae, thus contributing to ribbon formation around the centrosome. ${ }^{67}$

\section{Microtubule nucleation at the Golgi apparatus}

The centrosome is the major site for MT nucleation and anchorage in proliferating and migrating cultured animal cells. ${ }^{70}$ However, it has recently shown that the GA acts as an important secondary MT-organizing center (Figure 1B). ${ }^{17}$ Indeed, it has been estimated that almost half of all cellular MTs originate from the GA in human RPE1 cells. ${ }^{71}$ ChabinBrion et $\mathrm{al}^{72}$ showed for the first time that Golgi stacks were able to nucleate MTs in hepatic cells after NZ treatment. After drug washout, MTs apparently grew from scattered Golgi stacks. The authors further showed that purified Golgi membranes, which contained $\alpha$-, $\beta$-, and $\gamma$-tubulin, supported MT nucleation in vitro. Additional evidence for a direct role for GA in MT nucleation was obtained from the analysis of centrosome-free cytoplasts. In these cytoplasts, radial MT arrays were able to form and become centralized in a dynein-dependent manner. ${ }^{73}$ Strikingly, the GA appeared to be located at the center of centrosome-free cytoplasts, close to the MT aster. ${ }^{73}$ The unequivocal demonstration of GAassociated MT nucleation came from experiments of laser ablation of the centrosome in primary cells. ${ }^{71}$ By tracking polymerizing MTs in vivo, formation of MTs at Golgi stacks could be visualized either in normal or centrosome-lacking cells. MT nucleation at the GA was shown to require $\gamma$-tubulin complexes and the MT plus-end-binding CLASP proteins CLASP1 and CLASP2, which are recruited to the TGN through the interaction with the golgin GCC185. CLASPs are a family of MT-associated proteins that mainly bind 
plus-ends of MTs, and in this way they contribute to their stabilization. It was then proposed that CLASPs at the TGN could stabilize preexisting MT seeds by coating them, thus preventing their depolymerization.

However, these studies did not identify the molecular machinery required for MT nucleation at the GA. Rivero et $\mathrm{al}^{74}$ demonstrated that the centrosome GA-associated protein AKAP450 plays a key role in this process. AKAP450 is a giant coiled-coil protein of $450 \mathrm{kDa}$ that is recruited to the $\mathrm{cis}$ Golgi through its interaction with the golgin GM130 (Figure 1C). AKAP450 also interacts with $\gamma$-tubulin complexes, ${ }^{16,75}$ and might in this way confer MT-nucleation capacity to the cis-Golgi compartment. Indeed, depletion of Golgi-associated AKAP450 fraction completely abolished MT nucleation at the GA. In addition, dissociation of AKAP450 from the GA by GM130 knockdown also dissociated MT-nucleation ability from the GA. ${ }^{74}$ The GA-binding GM130-interacting domain was identified at the first N-terminal 300-aa coiledcoil stretch of the protein. ${ }^{76}$ Expression of this domain dissociated AKAP450 from GA and abolished MT nucleation at the GA, confirming the involvement of AKAP450 in MT nucleation at the GA. Altogether, these data indicate that GM130-mediated recruitment of AKAP450 to the cis-Golgi compartment enable this organelle to generate its own MTs. Supporting this model, the Drosophila homolog of AKAP450 (CP309) has been recently reported to play a pivotal role in acentrosomal MT nucleation from Golgi outposts within terminal and primary branches of class IV dendritic arborization neurons. ${ }^{22}$ MT nucleation from Golgi outposts in neurons required $\gamma$-tubulin in addition to AKAP450, and correlated with the extension and stability of terminal branches of dendrites.

Remarkably, two other centrosomal $\gamma$-tubulin ring complex $(\gamma$-TuRC)-binding proteins - CDK5Rap2 and myomegalin - have recently been reported to bind AKAP450 and to localize at the cis-GA in an AKAP450-dependent manner. ${ }^{77-80}$ CDK5RAP2 is a centrosome/GA protein that binds $\gamma$-tubulin complexes through the $\gamma$-TuRC-mediated nucleation activator motif. This motif directly binds to $\gamma$-TuRC and strongly stimulates its MT-nucleating activity. ${ }^{81}$ CDK5Rap2 is required for $\gamma$-TuRC association with the centrosome ${ }^{82}$ suggesting that it could play a similar role at the GA. Myomegalin is a CDK5Rap2 paralog in vertebrates, highly expressed in muscle tissue, which was identified as a centrosome/Golgi protein associated with cyclic nucleotide phosphodiesterase. ${ }^{83}$ Novel isoforms of myomegalin have recently been identified in nonmuscle cells. These myomegalin isoforms that localize predominantly to the cis-Golgi interact with AKAP450, $\gamma$-tubulin complexes, and the MT plus-end-tracking protein EB1. ${ }^{78,80}$ Interfering with the function of each of these proteins directly or indirectly perturbed MT nucleation at the GA, GA structural organization, and ER-to-GA transport.

Taken together, all these data support the idea that the cis-Golgi acquires the ability to nucleate MTs by acting as a preferential $\gamma$-TuRC-docking site, similarly to what it does at the centrosome. In addition, increasing evidence supports the idea that the MT-nucleating ability of the GA depends on multiprotein complexes similar to those operating at the pericentriolar material. In this scenario, AKAP450 appears as a key factor allowing the assembly of these multiprotein complexes at the surface of the $c i s$-Golgi cisternae. ${ }^{17}$ Since cytoplasmic pools of all these proteins exist, it is tempting to speculate that multiprotein complexes become competent for MT nucleation only after being assembled at the cis-Golgi membrane surface (or at the centrosome), in order to avoid random MT nucleation throughout the cytoplasm.

It should be taken into account that AKAP450 could also provide MT-formation/stabilization activities via additional mechanisms. For instance, AKAP450 also interacts with the dynactin subunit $\mathrm{p} 150^{\text {Glued }} \cdot{ }^{76,84}$ The $\mathrm{p} 150^{\text {Glued }}$-binding site is localized at the N-terminus of AKAP450 close to the GM130-interacting motif. When an AKAP450-truncated mutant containing both $\mathrm{p} 150^{\text {Glued }}$ and GM130-binding motifs was expressed, it targeted the GA and displaced endogenous protein from the Golgi. Interestingly, this truncated mutant also decorated cytoplasmic MTs, suggesting that AKAP450 could bind MTs through binding to $\mathrm{p} 150$ Glued ${ }^{76}$ These results, together with the finding that blocking dynein/dynactin interferes with GA-based MT nucleation at the GA, ${ }^{74}$ suggest that AKAP450 could participate in several ways in MT formation at the GA.

Newly nucleated MTs at the cis-GA need to be stabilized in order to prevent their disassembly. This would allow the formation of the dense meshwork of short MTs at the GA area that is found in the majority of cell types. As mentioned before, CLASP proteins seem to be essential in this process. Therefore, CLASPs and AKAP450-dependent multiprotein complexes should cooperate in the formation of this population of MTs.

How this cooperation occurs is far from clear. AKAP450 and CLASPs localize at opposite sides of Golgi stacks: AKAP450 localizes at the cis-Golgi, whereas CLASPs associate to the TGN. ${ }^{71,74}$ It was first proposed that very short MT fragments generated at the cis-Golgi would be stabilized by CLASP proteins at the TGN, allowing them to serve as seeds 
for polymerization. Alternatively, MT seeds could elongate from the cis face of Golgi stacks and subsequently be stabilized at their plus ends. This would generate a meshwork of short MTs within, and rather parallel to, the Golgi cisternae that may favor tangential linking and fusion of Golgi stacks into a Golgi ribbon. Additionally, CLASPs might stabilize MTs nucleated from the cis-Golgi that extends through the TGN toward the cell periphery, specially in migrating cells, in which Golgi-associated MT arrays are oriented toward the cell front. ${ }^{17,30}$

Other proteins can also cooperate in the stabilization of Golgi-based MTs. Among them, CAP350 is a centrosomal protein initially described as an MT-anchoring protein at the centrosome. ${ }^{85}$ It has been reported that CAP350 contributes to the maintenance of Golgi-ribbon positioning and integrity by specifically stabilizing a subset of MTs associated with the GA. ${ }^{86}$ Intriguingly, the suppressor tumor protein PTTG1/securin has been recently found to be associated with the GA in an MT-independent manner. ${ }^{87}$ It seems to exist in a complex with AKAP450, GM130, and $\gamma$-tubulin. Depletion of PTTG1 resulted in a delay of both centrosomal and GA-based MT nucleation. Based on these results, it has been proposed that PTTG1/securin might have a role as a chaperone contributing to the formation and stability of MTnucleating complexes. ${ }^{87}$

\section{Functions of Golgi-nucleated microtubules in cell dynamics}

Several recent studies have investigated the functions of Golgi-derived MTs. They have revealed that Golgi-based MTs participate in a wide range of cellular processes, including maintenance of Golgi morphology and integrity, Golgi reassembly after mitosis, directional cell migration, polarized secretion and ciliogenesis..$^{71,76,88-90}$

First insights on this issue came from live-cell imaging analysis of Golgi re-assembly during NZ recovery. ${ }^{90}$ It was shown that this assembly takes place in two different phases: first Golgi ministacks fuse into larger elements at the cell periphery, and then these peripheral clusters are transported to the cell center, where they tangentially connect to form a single-membrane unit. Golgi-derived MTs were essential for the first phase, since abolition of Golgi-nucleation ability led to a selective defect of peripheral clustering and initial fusion of dispersed Golgi elements. Under these circumstances, a circular GA surrounding the centrosome formed, but it was highly fragmented, as revealed by FRAP (fluorescence recovery after photobleaching) experiments. These results indicated that Golgi elements can be translocated toward the cell center in the absence of Golgi-nucleated MTs, but they are unable to fuse into a continuous Golgi ribbon. ${ }^{76,90}$ In a more physiological context, such as cell division, Golgi-nucleated MTs were shown to be responsible for Golgi reassembly at the end of mitosis. In the presence of a dominant negative mutant of AKAP450, Golgi stacks accumulated at spindle poles during telophase, but they remained small and fragmented, indicating that Golgi-associated AKAP450-dependent MT nucleation is essential to bring together emerging Golgi stacks in the course of postmitotic assembly. ${ }^{88}$ Fusion of Golgi stacks into a polarized Golgi ribbon is a complex process that implies both lateral linking and fusion of homotypic cisternae. Golgi-nucleated MTs that grow tangentially to stacks might participate in this process by allowing Golgi stacks to properly align, thus facilitating successive linking and fusion events.

One striking feature of Golgi-nucleated MTs is their asymmetry, which could be relevant for such cellular processes as directional secretion or cell migration. Indeed, polarized post-Golgi trafficking was impaired in conditions where Golgi MT-nucleation ability was abolished. ${ }^{76,90}$ In the same way, cells lacking Golgi-derived MTs migrated slower in wound-healing assays in spite of proper coordinated reorientation of both the centrosome and the GA toward the leading edge. ${ }^{76,90}$ Since in the absence of Golgi-nucleated MTs, Golgi stacks localized around the centrosome but remained unfused, one might conclude that Golgi-ribbon integrity is more important for these processes that its pericentrosomal position. The interference with AKAP450 function supported the view that the pericentrosomal position of the Golgi ribbon is a more determinant factor for cell polarity and directional migration than Golgi-ribbon integrity. ${ }^{76}$ Indeed, disruption of Golgi-centrosome association induced by the expression of the N-terminus of AKAP450 had a stronger negative effect on cell polarity and migration than simply inhibiting MT nucleation. This is in agreement with previous evidence that motile cells require a polarized Golgi complex in proximity to the centrosome for proper directional post-Golgi trafficking and directional cell migration. ${ }^{91}$

\section{The actin-based cytoskeleton and the Golgi apparatus}

The first experimental evidence that actin and the Golgi may interact occurred when Golgi membranes and Golgiderived vesicles contained actin and actin-binding proteins. ${ }^{92}$ Furthermore, the Golgi invariably compacted when cells were treated with naturally occurring substances that perturbed the actin organization and its dynamics, which mainly include 
cytochalasins, latrunculins, jasplakinolide, and botulinum toxins and are known generically as actin toxins or actin drugs $^{93-97}$ (Figure 2, top row). At an ultrastructural level, the compacted Golgi was seen to depend on whether actin drugs depolymerized or stabilized actin filaments, giving rise respectively to dilatation or fragmentation/perforation of cisternae (Figure 2, bottom row). Moreover, these ultrastructural impairments occurred in an MT-independent manner, which ruled out synergic cooperation between MTs and actin filaments controlling the shape and integrity of Golgi cisternae. ${ }^{94}$ Golgi compactness is consistently seen when actin partners present at the Golgi complex are perturbed, such as after the depletion of the Arp2/3 activator WHAMM (WASp homolog associated with actin, Golgi membranes, and MTs), ${ }^{98}$ cortactin, ${ }^{99}$ or myosin $18 \mathrm{~A}$, an unconventional myosin that connects filamentous actin to the phosphatidylinositol 4-phosphate (PI4P)-binding protein GOLPH3. ${ }^{100,101}$ However, in some cases, interference with the actin machinery produces fragmentation (and dispersion) of the Golgi, which occurs after the depletion or constitu- tive activation of actin nucleator formin family members mDia, the formin-like 1/FMNL1, and INF2. ${ }^{102-104}$ Taken together, these findings reinforce the notion that the proper regulation of actin at the Golgi is necessary to maintain the structural integrity of the GA. In Figure 3 are summarized the different steps in which actin and actin-binding/regulatory proteins have been firmly established, and these are further developed here.

By analogy with erythrocytes, the Golgi-associated spectrin skeleton could act as an extended, two-dimensional interactive platform on the cytoplasmic surface of cisternae, regulating its shape and transport functions. ${ }^{105-109}$ While mammalian red blood cells contain only one type of spectrin tetramer ( $\alpha \mathrm{I} \beta \mathrm{I}$ subunits), nucleated cells contain numerous isoforms of both subunits, with $\beta$ III spectrin being localized to the Golgi. ${ }^{110,111}$ Other isoforms of the spectrin-based cytoskeleton components typically present in the plasma membrane of red blood cells have also been localized in the Golgi, such as $\beta$ - and $\gamma$-actin, ${ }^{97}$ ankyrins $\mathrm{Ank}_{\mathrm{G} 119}$ and Ank $_{195},{ }^{112-114}$ protein 4.1B, ${ }^{115}$ anion exchanger AE2, ${ }^{116,117}$ and
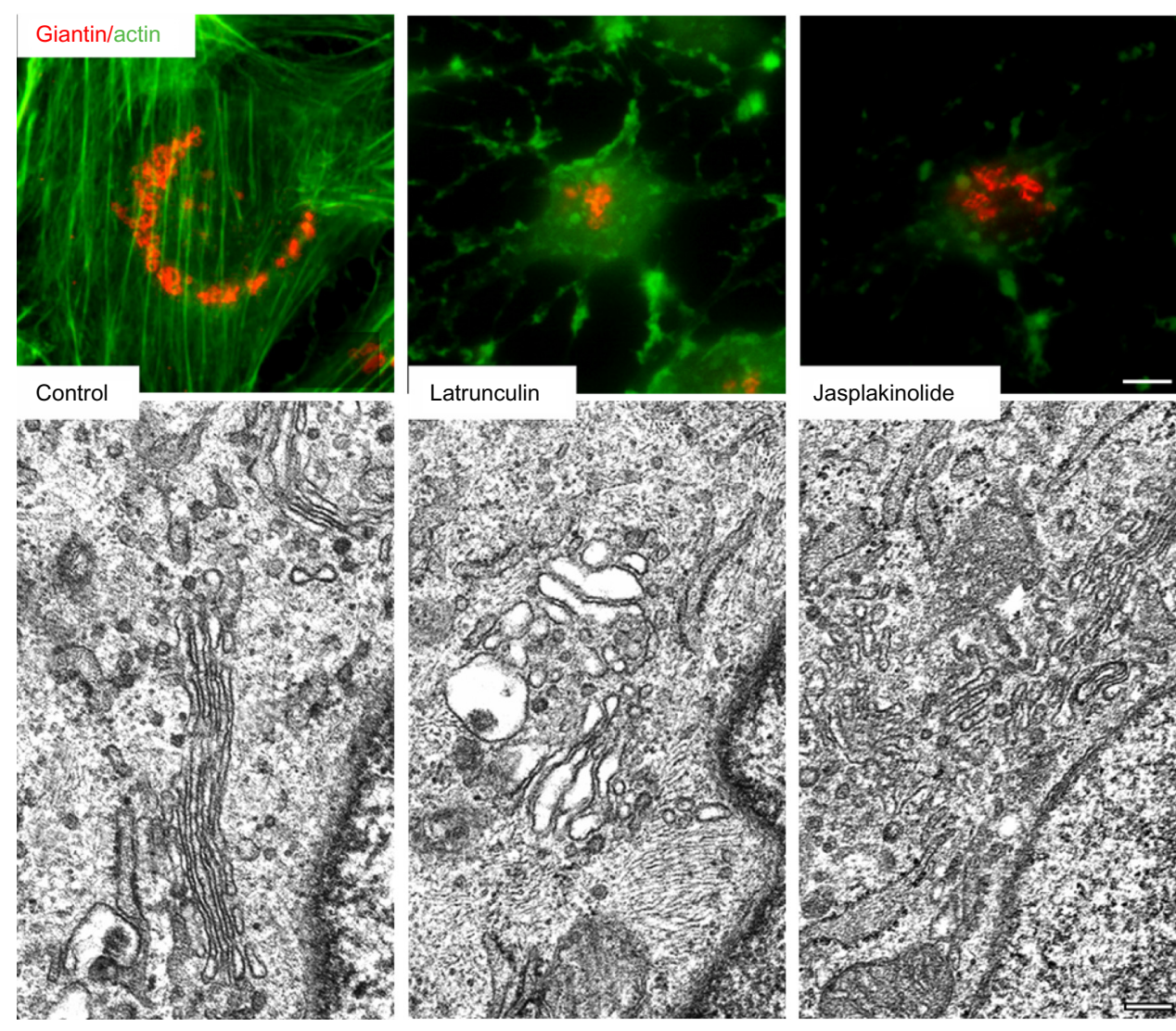

Figure 2 Actin-Golgi interaction I.

Notes: Immunofluorescence microscopy image of NRK cells double-labeled for filamentous actin (with phalloidin-fluorescein isothiocyanate [green]) and for the Golgimatrix protein giantin (with antibodies to giantin [red]). Untreated cells (control) and cells treated with antiactin agents, such as latrunculin (actin depolymerizer) or jasplakinolide (actin stabilizer), are shown. Notice the characteristic compaction of the Golgi caused by both toxins. However, under the electron microscope, their effects on the Golgi ultrastructure are very different: latrunculin leads to the swelling of cisternae, while jasplakinolide causes their fragmentation. Bars, 5 and $0.2 \mu M$, respectively. 


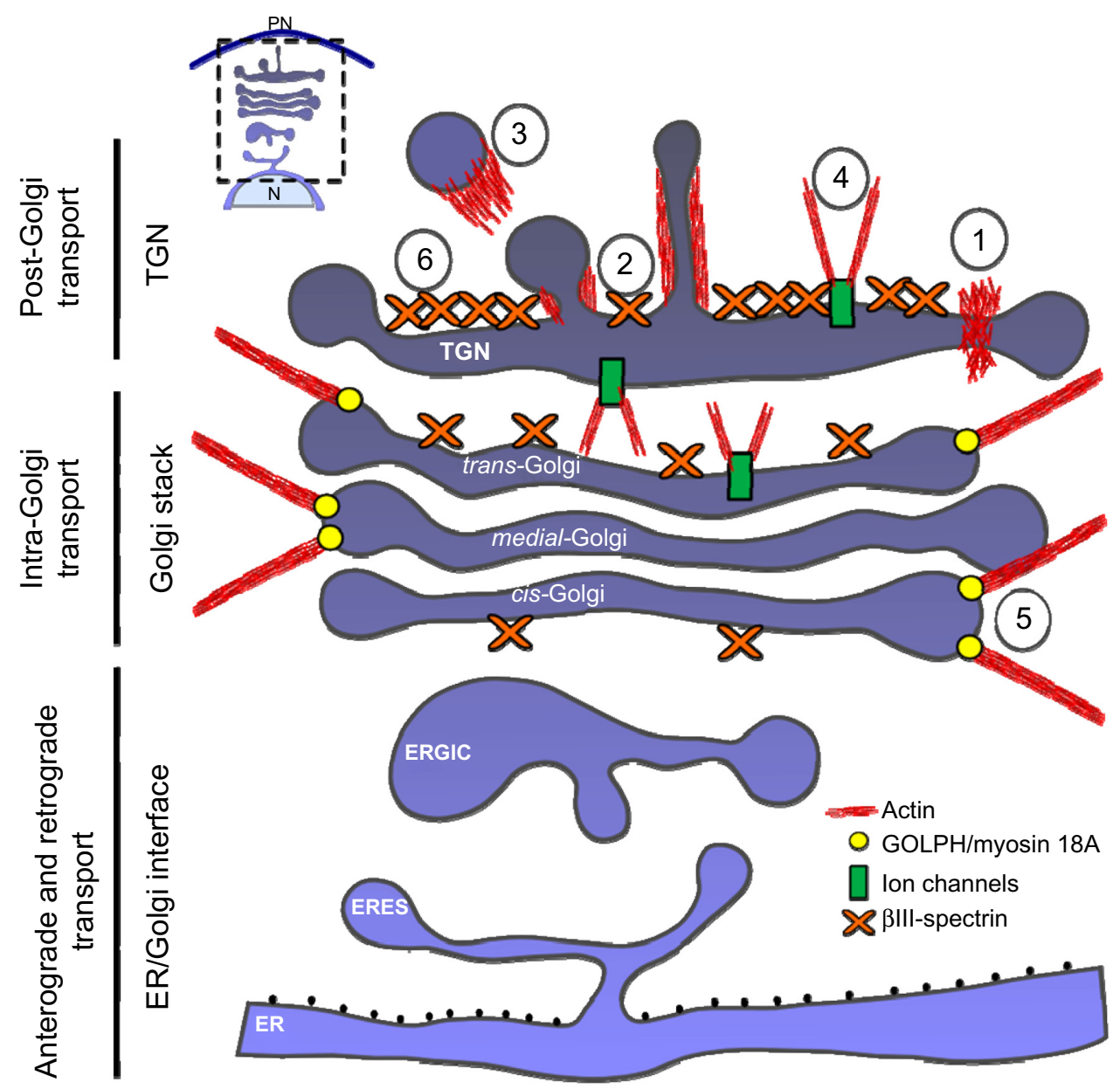

Figure 3 Actin-Golgi interaction II.

Notes: Diagram of the secretory membrane trafficking pathways and events in which actin is known to participate. Actin filaments, their polymerization, and dynamics could act as a force for the scission (1), pulling (2), and propelling (3) of the transport carrier generated in cisternae, and for maintaining the flattened shape of cisternae through the regulation of the activity on some ion pumps/channels (4) and/or being part of the spectrin-based cytoskeleton (6), and to keep the Golgi ribbon extended (5). Modified from Springer, Histochemistry and Cell Biology. Actin acting at the Golgi. 20I 3; I40(3):347-360. Egea G, Serra-Peinado C, Salcedo-Sicilia L, Gutiérrez-Martínez E. Copyright ( Springer-Verlag Berlin Heidelberg 2013, with kind permission of Springer Science+Business Media. ${ }^{24}$

Abbreviations: TGN, trans-Golgi network; ERGIC, endoplasmic reticulum-Golgi intermediate compartment; ERES, ER exiting sites.

tropomyosin. ${ }^{118} \beta \mathrm{III}$ spectrin maintains Golgi architecture, since its functional interference or knockdown causes fragmentation and dilation of Golgi membranes. ${ }^{110,119}$ It is possible that the Golgi fragmentation is produced by the loss of the direct interaction of $\beta I I I$ spectrin with the dynein-dynactin motor-complex subunit Arp1, ${ }^{120}$ and distal cisternae swelling is caused by alterations in the activity of ionic channels, in the mechanical stability of cisternae, or both. Strikingly, actin toxins did not perturb the localization of $\beta I I I$ spectrin at the Golgi, which indicates that actin dynamics do not participate in the association of $\beta \mathrm{III}$ spectrin with Golgi membranes, but PI4P was crucial in such interaction. ${ }^{110}$ The ultrastructural alterations caused by actin drugs ${ }^{94}$ and the depletion of $\beta I I I$ spectrin $^{110}$ indicate that they provide mechanical stability to cisternae. Ion-regulatory molecules, such as vacuolar $\mathrm{H}^{+}$-ATPase ${ }^{121}$ and cation exchangers $\left(\mathrm{Na}^{+} / \mathrm{H}^{+}\right.$exchangers $),{ }^{122}$ either resident in the Golgi or in transit to the plasma membrane, could contribute to this cisternae mechanical stability, finely regulating intra-Golgi ion concentration and $\mathrm{pH}$ homeostasis. In this, sense actin filament-severing protein $\mathrm{ADF} /$ cofilin participates in cargo sorting at the TGN by activating the calcium ATPase 1 (SPCA1). ${ }^{123-125}$ In addition, cisternae swelling induced by latrunculin is accompanied by a rise in the intra-Golgi $\mathrm{pH} .{ }^{94}$ Therefore, actin seems to regulate the activity of some ionic regulatory proteins present in Golgi membranes, similar to what occurs at the plasma membrane. ${ }^{126}$

\section{Actin in the sorting, biogenesis, and motion of transport carriers at the Golgi}

A key aspect in the structure of polarized cells is the maintenance of polarized molecular organization. This is based on 
highly specific sorting machinery at the exit of the TGN. ${ }^{127}$ Cytoskeleton elements form part of this machinery, and the integrity of actin filaments is necessary for efficient delivery of some proteins destined for the apical or the basolateral plasma membrane domains in both polarized and unpolarized cells, but not for the transport of lipid raft-associated proteins. $^{128}$

\section{Rho GTPases and actin-polymerization molecular machinery}

The coupling between Golgi-associated actin polymerization and membrane-elongation and fission reactions must be subjected to control to prevent the structural and functional collapse of the Golgi. Rho GTPases and downstream effectors in Golgi membranes are essential to this aim. Rho GTPases cycle between active GTP-bound and inactive GDP-bound forms with the participation of guanine nucleotide-exchange factors (GEFs), GTPase-activating proteins (GAPs), and guanine nucleotide-dissociation inhibitors. $\mathrm{Cdc} 42$, which was the first Rho GTPase to be localized in the Golgi, ${ }^{129-134}$ affects the ER-Golgi interface and post-Golgi intracellular trafficking. ${ }^{135}$ Constitutively active and inactive $\mathrm{Cdc} 42$ mutants block the ER-to-Golgi transport of anterograde cargo (VSV-G). ${ }^{134}$ The overexpression and activation of $\mathrm{Cdc} 42^{131}$ or the knockdown of Cdc42 GAP ARHGAP21 (also known as ARHGAP10) ${ }^{136}$ inhibits the Golgi-to-ER transport of retrograde cargo (Shiga toxin). Cdc42 directly binds to the coatomer or COPI system, particularly the $\gamma$ COPI subunit, recruiting N-WASP and Arp2/3 to Golgi membranes. A receptor for cargo containing the dilysine motif in the $\mathrm{COOH}$ terminal, p23 competes with Cdc42 for binding to the $\gamma$ COPI subunit. Cargo loading by p23 disrupts $\mathrm{Cdc} 42-\gamma \mathrm{COP}$ interaction and recruits dynein to promote dynein-dependent ER-to-Golgi transport. ${ }^{137}$ Therefore, Cdc42 coordinates actin- and MT-dependent motility of transport carriers at the ER-Golgi interface. ${ }^{138}$ In post-Golgi trafficking, the expression of constitutively active or inactive $\mathrm{Cdc} 42$ mutants slows the exit of basolateral protein markers and accelerates the exit of apically destined ones. ${ }^{139-141}$ ARHGAP21/10 and Cdc42 GEFs Fgd1 and Dbs are also present in Golgi membranes regulating post-Golgi vesicular transport. ${ }^{142-144}$

Besides $\mathrm{Cdc} 42$, recent evidence indicates that other Rho GTPases are working at the Golgi. Therefore, we have 1) RhoA with the actin nucleator mDia or mammalian diaphanous-related formin 1, ${ }^{104}$ which accelerates actin nucleation and elongation by interacting with barbed ends of microfilaments, and the neuronal RhoA-associated protein citron- $\mathrm{N},{ }^{145}$ which assembles together the Rho effector ROCK
II and the actin-binding, neuron-specific, protein profilin IIa.

2) RhoD with the WAS (Wiskott-Aldrich syndrome) protein homolog associated with actin, Golgi membranes, and MTs (WHAMM), ${ }^{146}$ which plays a role in actin nucleation, Golgi-membrane association, and MT binding. WHAMM is a nucleation-promoting factor that regulates the actin-related protein $2 / 3$ complex. The activated complex initiates growth of new actin filaments by binding to existing actin filaments. WHAMM also functions in regulation of transport from the ER to the Golgi complex and in maintenance of the Golgi complex near the centrosome. And finally we have 3) Rac1 and its exchange factor $\beta$-PIX with the clathrin heavy chainbinding protein CYFIP/Sra/PIR121. ${ }^{147}$ RhoD-WHAMM and the ARF1-primed Rac1-CYFIP/Sra/PIR121 protein complexes stimulate the Arp2/3-induced actin polymerization at the Golgi and vesicle biogenesis. ${ }^{98,147}$ The ROCK/LIM kinase (LIMK) signaling pathway and its substrate cofilin are necessary for apical cargoes. ${ }^{148,149}$ RhoA GEF-H1 interacts with exocyst component Sec5, which in turn activates RhoA regulating post-Golgi trafficking and assembly of other exocyst components. ${ }^{150}$

The presence in Golgi membranes of molecular components that trigger actin polymerization with those that control vesicular budding and fission suggests intimate molecular coupling between them, which is similar to that observed during endocytosis. ${ }^{151}$ Actin assembly provides the structural support and generates force for the formation of transport carriers in the lateral portions of Golgi membranes, which is facilitated by actin nucleators and accompanied by the mechanical activity of actin motors (myosins). In accordance with this idea, Arp2/3, mDia, formin-like 1/FMNL1 and INF2, and Spir1 are all present in the Golgi. ${ }^{132,152-154}$ At the TGN, there is a functional coupling between dynamin-mediated membrane fission and Arp2/3mediated actin-based mechanisms. ${ }^{152,154-158}$ Interference with dynamin 2 /cortactin or dynamin 2 /syndapin 2 /cortactin blocks post-Golgi protein transport. ${ }^{155,159}$ As indicated earlier, in early Golgi compartments there is a functional connection between actin polymerization governed by $\mathrm{Cdc} 42$, coatomer (COPI)-mediated transport-carrier formation, and MT motor-mediated motion. WASH (WAS protein and SCAR homolog) is another Arp2/3 activator that regulates cation independent-mannose phosphate receptor (CI-MPR) trafficking from endosomes to the Golgi, forming an endosomal subdomain containing Arp2/3, F-actin, tubulin, and retromer components. ${ }^{160}$ The local fine regulation of actin dynamics on the transport-carrier assembly represents an early step that precedes its scission taking place in the 
lateral rims of cisternae for subsequent switching to MT tracks for motion.

On the other hand, actin nucleation/polymerization activity associated with $\mathrm{Arp} 2 / 3$ could give also rise to the formation of actin comet tails, which consist of filamentous actin and various actin-binding proteins that focally assemble and grow on a membrane surface. ${ }^{161}$ After the overexpression of phosphatidylinositol 5-kinase, actin tails have been observed in raft-enriched TGN-derived vesicles. ${ }^{158} \mathrm{An}$ in vitro approach in liposomes showed actin polymerization occurring after the recruitment of the activated form of ARF1 around liposomes. This actin polymerization was dependent on $\mathrm{Cdc} 42$ and N-WASP, and resulted in the formation of actin comets, which pushed the ARF1-containing liposomes forward. ${ }^{162}$ However, actin comet tails do not seem to be an efficient mechanism to provide precise directionality for transport carriers. Also, an actin comet tail-like mechanism could easily provide brief local force to facilitate the final separation of the transport carrier at the lateral rims of Golgi cisternae similarly to what happens during endocytosis, ${ }^{163,164}$ and/or for its translocation to closely arranged MT tracks. ${ }^{165}$

\section{Myosin motors and actin itself as molecular and mechanical constraints}

In addition to actin polymerization, myosins also generate a force that can selectively couple protein sorting and transportcarrier biogenesis and motility. Class I myosin is a monomeric, nonprocessive motor that binds to Golgi membranes and is present on apical Golgi-derived vesicles of polarized cells. ${ }^{166-170}$ Myosin Ib together with actin polymerization have recently been shown to participate in membrane remodeling to form tubular transport carriers at the TGN directed to endosomes and the plasma membrane. ${ }^{166,171}$ It has been hypothesized that myosin Ib spatially controls actin assembly at the TGN, interacting with F-actin via its motor domain and at the membrane via its $\mathrm{PH}$ domain. Such interaction generates a force concomitantly with the polymerization of actin, leading to membrane-curvature changes. ${ }^{171,172}$ Coudrier and Almeida suggested coordination between myosin $1 \mathrm{~b}$ and nonmuscle myosin II for the scission of tubular carriers at the TGN. ${ }^{171}$ Myosin Ic controls the delivery of GPI-linked cargo proteins to the cell surface from the endosomal recycling compartment, ${ }^{173}$ but this does not seem to be the case for myosin Ib, either at the TGN or in endosomes. ${ }^{166}$

Nonmuscle myosin II is another nonprocessive motor that interacts with Golgi membranes ${ }^{174}$ and mediates Golgito-ER and post-Golgi protein transport. ${ }^{175-178}$ It has been hypothesized that myosin II is tethered to the cisterna by its tail and to actin filaments by its motor head. Its subsequent motion along actin filaments could provide the force needed to extend Golgi-derived membranes away from the cisterna, which could facilitate the functional coupling of membrane scission protein(s), leading to the release of the transport carrier. In this respect, myosin II forms a complex with Rab6, which drives its localization to Golgi membranes and controls the fission of anterograde and retrograde Rab6 transport carriers. ${ }^{179}$ The Golgi-associated tropomyosin isoform ${ }^{118}$ could stabilize short actin filaments formed locally in the cisternae lateral rims during vesicle biogenesis. These short actin filaments together with myosin II could equivalently act as a sarcomeric-like system to generate the force necessary to split transport carriers. Accordingly, there is an abnormal accumulation of uncoated vesicles close to cisternae after the knockdown of myosin II or the pharmacological blockade of its motor activity. ${ }^{176,180}$ Many of them remain attached to cisternae, which argues in favor of the participation of myosin II in the fission process. ${ }^{179}$ However, in another line of evidence, myosin II has been reported to be required only for motion but not for the biogenesis of PKD-dependent transport carriers at the TGN. ${ }^{181}$

With regard to myosin $\mathrm{V}$, it has been recently reported that myosin Va interacts with only a subset of the Rabs associated with the endocytic recycling and post-Golgi secretory systems. ${ }^{182}$

Myosin VI is another myosin motor located in the Golgi. ${ }^{183,184}$ It is a processive myosin that moves to the fast-depolymerizing minus-end pole of the microfilament. Myosin VI is involved, among many others in the maintenance of Golgi morphology. ${ }^{184,185}$ The interaction between myosin VI and optineurin, a partner of Rab8, ${ }^{185}$ acts at the TGN of polarized epithelial cells in the protein sorting and basolateral transport mediated by the clathrin adaptor-protein complex AP-1B. ${ }^{186}$ Therefore, the known role of some Rab proteins as linkers of endocytic membranes to cytoskeletal motors is now also extended to the Golgi. ${ }^{187}$

Unconventional myosin 18A has also been located in distal Golgi membranes, where it binds to the PI4P-binding protein GOLPH3. It has been suggested that the GOLPH3Myos18 interaction couples actin filaments to Golgi membranes, and the tension generated by this interaction facilitates the maintenance of the extended Golgi-ribbon organization and flattens Golgi cisternae. In addition, it also seems to support secretory function, because the depletion of GOLPH3 blocks the exit of VSV-G from the TGN. ${ }^{100}$ The contribution of this unconventional myosin to Golgi-associated membrane trafficking requires further characterization, because 
it exhibits low motor activity. ${ }^{188}$ Nonetheless, it has been recently reported that GOPPH3 links deoxyribonucleic acid (DNA) damage with Golgi fragmentation and dispersion, ${ }^{189}$ revealing the DNA-PK-GOLPH3-MYO18A pathway to be necessary for cell survival upon DNA damage.

It is reasonable to think that as occurs with molecular forces (represented by actin motors), physical ones could also contribute to the shape, organization, and function of endomembranes in general and on the Golgi in particular. Whereas great progress has been made in addressing the contribution of membrane tension and curvature to coatinduced budding and molecular sorting and to membrane fission of transport carriers using in vitro systems, ${ }^{190}$ the in vivo approach has remained elusive, mainly for technical reasons. However, a recent study in which optical tweezers were combined with confocal microscopy in living cells revealed that Golgi membranes are flexible and mechanically coupled, that actin confers rigidity to the GA, and that a mechanical constraint produces a switch from vesicular to tubular trafficking, linking forces with membrane fission. ${ }^{191}$ The diagram shown in Figure 3 summarizes the variety of molecular processes in which actin or actin-based machinery has been reported at the Golgi in mammalian cells.

\section{The Golgi apparatus-actin interaction in other cellular systems}

\section{Plant cells}

Stationary actin filaments or actin bundles are the most prominent cytoskeleton element in plant cells. Attached to the actin bundles are the ER, vesicles, and numerous discrete clustered Golgi stack-TGN units, also known as Golgi bodies. They are highly variable in number (from a few tens to hundreds), depending on the plant-cell type and its developmental stage. ${ }^{7,10}$ In polarized root hairs and pollen tubes, the TGN is segregated from Golgi bodies, which localize to growing tips, where together with actin, Rho/Rac members (ROPs and Rac1, respectively), Rab (Rab4a and Rab11), and ARF (ARF1) small GTPases regulate secretory and endocytic trafficking. ${ }^{192}$ Also in this cell type, the motility and positioning of Golgi bodies is highly dependent on the actin organization, being faster and directional in areas containing actin-filament bundles and slower and nondirectional in areas with fine filamentous actin. ${ }^{193}$

In plants, most of the endomembrane compartments are in constant movement together with the cytoplasmic streaming whereby cellular metabolites are distributed throughout the cell. ${ }^{194}$ Golgi bodies show actin-dependent dispersal and spatial organization. ${ }^{195,196}$ They contain a fine fibrillar material that is enriched in actin and spectrin- and myosinlike proteins. ${ }^{197,198}$ The depolymerization of microfilaments with actin toxins uncouples the association between specific regions of the cortical ER with individual Golgi bodies; ${ }^{195,196}$ however, and in contrast to animal cells ${ }^{96}$ it does not perturb the brefeldin A (BFA)-induced Golgi disassembly. ${ }^{199}$ Therefore, cytochalasin or latrunculin treatments induce the aggregation of Golgi bodies and variably alter the Golgi morphology depending on the cell type and the period of treatment. ${ }^{198,200}$ Actin toxins also perturb the coordinated movement of Golgi bodies and ER tubules. ${ }^{11,201}$ Actin does not participate in ER-Golgi interface protein transport, ${ }^{202}$ but it does contribute to post-Golgi trafficking to the plasma membrane and the vacuole. In the tip of growing cells like pollen tubes, actin filaments are the tracks through which Golgi-derived secretory vesicles are transported. ${ }^{203,204}$ An intact actin-myosin system is required for the transport of cargo containing polysaccharides and the enzymes necessary for cell-wall morphogenesis, and the local differences in the actin-cytoskeleton organization determine where their secretion is required. ${ }^{89,205-207}$ Golgi bodies are also propelled by plant myosin-family members, particularly the myosin XI class. ${ }^{208}$

\section{Yeast}

Most components of the secretory pathway and many of the actin-based cytoskeleton are conserved between yeast and mammalian cells. ${ }^{209,210}$ The actin cytoskeleton in yeast consists primarily of cortical patches and cables. ${ }^{211-213}$ Many actin mutants accumulate large secretory vesicles and exhibit phenotypes consistent with defects in polarized growth, ${ }^{214,215}$ which together with the polarized organization of actin cytoskeleton has suggested a role for actin in the positioning and orientation of the secretory pathway and polarized transport of late secretory vesicles to the plasma membrane. ${ }^{210,216}$ A mutation of GRD20, a protein involved in sorting in the TGN-endosomal system, showed defects in the polarization of the actin cytoskeleton and impaired secretion of vacuolar hydrolase carboxypeptidase Y (but not other TGN-membrane proteins). ${ }^{216}$ The actin-severing protein cofilin and Pmr1, the yeast ortholog of the secretory pathway calcium ATPase 1 (SPCA1), are both required for sorting at the late Golgi compartment. ${ }^{123}$ Overexpression of Av19p produces vesicle accumulation and a post-Golgi defect in secretion, and its depletion in a strain that also lacks Vps1 (dynamin) and Apl2 (adaptor-protein complex 1) impaired actin-cytoskeleton organization and caused defects in polarized secretion. ${ }^{217}$ Concentration of late (but not early) Golgi elements at the 
yeast bud (the site of polarized growth) depends on actin, which is transported along actin cables by yeast myosin $\mathrm{V}$ (Myo2). ${ }^{218}$ Crucial in this process is Ypt11, a Rab GTPase that interacts with Myo2 and Ret2, a subunit of the coatomer complex. The polarization of late Golgi cisternae in the bud is not produced in the Ypt1 $1 \Delta$ mutant. ${ }^{219}$ The Rab protein Ypt31/32 present at the TGN directly interacts with Myo2 and the secretory vesicle Rab Sec4, whose interaction is modulated by PI4P levels. ${ }^{220}$ Moreover, the Ypt31/32-Myo2-Sec4 complex interacts with the exocyst subunit Sec15, regulating post-Golgi trafficking and cell growth. ${ }^{221}$

In the early secretory pathway, actin depolymerization with actin toxins does not affect ER-to-Golgi protein transport, ${ }^{222}$ but it does affect retrograde Golgi-to-ER trafficking, which is regulated by the ubiquitin ligase Rsp5, a protein that forms a complex containing COPI subunits and has as substrates the actin-cytoskeleton proteins Sla1, Lsb1, and Lsb2, which bind to the Arp2/3 activator Las 17. ${ }^{223,224}$

\section{Drosophila}

The Drosophila cellular model is an alternative to yeast to study the Golgi, because it shares many structural and functional similarities with the mammalian model, but importantly most Drosophila cells lack the characteristic mammalian Golgi ribbon. Instead, they present a scattered and fairly constant number of what are known as ER-Golgi units, which are ultrastructurally constituted by a pair of Golgi stacks. ${ }^{225}$ The integrity of the actin cytoskeleton is crucial for Golgi-stack pairs, since actin depolymerization causes their splitting and perturbs Golgi inheritance, which requires duplication to form the paired structure. Abi and Scar/WAVE (but not WASP) are necessary in this process. ${ }^{226}$ The inactivation of the golgin-like MT/actin-binding protein lava lamp prevents the necessary Golgi dispersal in the cellularization process. ${ }^{227,228}$ Drosophila S2 cells showed that the depletion of the $t s r$ gene (which codifies for destrin, also known as ADF/cofilin) aggregated and dilated Golgi membranes, inhibiting HRP secretion. ${ }^{229}$ The mutant coronin proteins dpdo1 and coro, which regulate the actin cytoskeleton and govern biosynthetic and endocytic vesicular trafficking, severely perturbed embryonic development due to abnormal cell division and aberrant formation of essential morphogen gradients. ${ }^{230}$

\section{Dictyostelium discoideum}

Cells of this social amoeba contain various types of vacuole, ER, and small Golgi stacks. ${ }^{231}$ Comitin (p24) is a dimeric Dictyostelium actin-binding protein present in the Golgi and vesicles that binds Golgi-derived vesicles to the actin filaments via the cytoplasmic exposed mannosylated glycans. ${ }^{232,233}$ Villidin is another actin-binding protein that associates with secretory vesicles and Golgi membranes. ${ }^{234}$ The centrosomal protein LIS1 (DdLIS1) links MTs, the nucleus, and the centrosome, and indirectly controls Golgi morphology. Mutants of this protein lead to MT disruption, Golgi fragmentation, and actin depolymerization. ${ }^{235}$ AmpA is a secreted protein necessary for cell migration in an environment-dependent manner that also participates in the regulation of actin polymerization. It is found in the Golgi, but transported to the plasma membrane, where it regulates endocytosis. ${ }^{236}$ In addition to Rho GTPases, Dictyostelium also contains other Rho-regulated signaling components, such as Rho nucleotide-dissociation inhibitors, the Arp2/3 complex, PAK, WASP, Scar/WAVE, formins, GEFs, and GAPs. ${ }^{237}$ The acquisition of cell polarity during chemotaxis needs WASP, which localizes on vesicles whose formation in the Golgi requires the interaction between WASP with the pombe $\mathrm{Cdc} 15$ homology ( $\mathrm{PCH}$ )-family protein members Nwk/Bzzl-p-like and syndapin-like proteins. ${ }^{238} \mathrm{RacH}$ is a closer protein to Rac and $\mathrm{Cdc} 42$ that localizes to compartments of the secretory pathway (nuclear envelope, the ER, and the Golgi) where it stimulates actin polymerization, and it also seems to be involved in actin-based trafficking of vesicles, but in contrast to AmpA, it is uncoupled from chemotaxis. $^{239}$

\section{Conclusion}

The positioning, architecture, and trafficking of the GA, which varies greatly in shape and number from one organism to another, is highly dependent on the cytoskeleton, particularly MTs and actin filaments. The cytoskeleton imposes the localization of the GA and determines its structure and function in terms of cargo segregation and transport-carrier formation. In most mammalian cells, the GA is organized in a ribbon-like shape and localized around the centrosome in the cell center. The centrosome is the major MT-organizing center in animal cells. It is responsible for organizing a radial MT network during interphase and the mitotic spindle during cell division. Recently, MT-nucleating activity has also been found to be associated with the GA. Both centrosome- and Golgi-nucleated MTs participate in ensuring the structural integrity of the Golgi ribbon and its pericentrosomal position, which could be relevant in processes that involve Golgi reformation, such as cell division. Translocation of transport carriers from the ER to the GA (anterograde transport) and from the GA to the ER (retrograde transport) also depends on 
MTs and involves MT motors of opposite polarity, ie, dynein and kinesins, respectively. In addition to molecular motors, the Golgi-associated molecular machinery involved in the motion of transport carriers and nucleation of MTs includes Rab proteins (Rab6), coiled-coil proteins (golgin-160 and GMAP210), MT-stabilizing proteins (CLASPs), and centrosome-Golgi-associated proteins (AKAP450). On the other hand, in animal cells, the actin-dependent cytoskeleton is highly relevant in early events in the formation of Golgiderived transport carriers, such as sorting and membrane fission. Actin is also necessary to maintain the characteristic flattened shape of cisternae. A wide actin-associated molecular machinery is documented, such as actin nucleators (ARP2/3 and formin-family members), actin regulators, effectors and binding proteins (RhoA, Rac1, Cdc42, N-WASP, and cortactin, among others), and actin motors (myosins I, II, VI, and 18). Altogether, this causes a fine regulation of the formation of retrograde and post-Golgi transport carriers, in which mechanical forces associated with local actin polymerization play a relevant role. In summary, MTs and actin filaments act in an almost indissoluble and coordinated manner in the architecture and function of the GA in many cellular systems.

\section{Acknowledgments}

We are grateful to our respective past and present lab members for valuable discussions and support, and RMR particularly to M Arjona and C Marcozzi. Research in GE's and RMR's labs is supported by grants from the Ministerio de Economia y Competitividad (BFU2009-07186 and BFU2012-33932 to GE, and BFU2012-36717 and CSD200900016 to RMR). RMR's lab is also supported by the Consejo Superior de Investigaciones Científicas and the Junta de Andalucía (Spain).

\section{Disclosure}

The authors report no conflicts of interest in this work.

\section{References}

1. Rambourg A, Jackson CL, Clermont Y. Three dimensional configuration of the secretory pathway and segregation of secretion granules in the yeast Saccharomyces cerevisiae. J Cell Sci. 2001;114(Pt 12): 2231-2239.

2. Preuss D, Mulholland J, Franzusoff A, Segev N, Botstein D. Characterization of the Saccharomyces Golgi complex through the cell cycle by immunoelectron microscopy. Mol Biol Cell. 1992;3(7): 789-803.

3. Henderson GP, Gan L, Jensen GJ. 3-D ultrastructure of $O$. tauri: electron cryotomography of an entire eukaryotic cell. PLoS One. 2007; 2(1):e749.

4. Pelletier L, Stern CA, Pypaert M, et al. Golgi biogenesis in Toxoplasma gondii. Nature. 2002;418(6897):548-552.
5. He CY. Golgi biogenesis in simple eukaryotes. Cell Microbiol. 2007; 9(3):566-572.

6. He CY, Ho HH, Malsam J, et al. Golgi duplication in Trypanosoma brucei. J Cell Biol. 2004;165(3):313-321.

7. Képès F, Rambourg A, Satiat-Jeunemaitre B. Morphodynamics of the secretory pathway. Int Rev Cytol. 2005;242:55-120.

8. Rossanese OW, Soderholm J, Bevis BJ, et al. Golgi structure correlates with transitional endoplasmic reticulum organization in Pichia pastoris and Saccharomyces cerevisiae. J Cell Biol. 1999;145(1):69-81.

9. Mogelsvang S, Gomez-Ospina N, Soderholm J, Glick BS, Staehelin LA Tomographic evidence for continuous turnover of Golgi cisternae in Pichia pastoris. Mol Biol Cell. 2003;14(6):2277-2291.

10. Hawes C, Satiat-Jeunemaitre B. The plant Golgi apparatus - going with the flow. Biochim Biophys Acta. 2005;1744(2):93-107.

11. daSilva LL, Snapp EL, Denecke J, Lippincott-Schwartz J, Hawes C, Brandizzi F. Endoplasmic reticulum export sites and Golgi bodies behave as single mobile secretory units in plant cells. Plant Cell. 2004;16(7):1753-1771.

12. Kondylis V, Rabouille C. A novel role for dp115 in the organization of tER sites in Drosophila. J Cell Biol. 2003;162(2):185-198.

13. Rios RM, Bornens M. The Golgi apparatus at the cell centre. Curr Opin Cell Biol. 2003;15(1):60-66.

14. Yadav S, Linstedt AD. Golgi positioning. Cold Spring Harb Perspect Biol. 2011;3(5):a005322.

15. Infante C, Ramos-Morales F, Fedriani C, Bornens M, Rios RM. GMAP-210, a cis-Golgi network-associated protein, is a minus end microtubule-binding protein. J Cell Biol. 1999;145(1):83-98.

16. Takahashi M, Shibata H, Shimakawa M, Miyamoto M, Mukai H, Ono Y. Characterization of a novel giant scaffolding protein, CG-NAP, that anchors multiple signaling enzymes to centrosome and the Golgi apparatus. J Biol Chem. 1999;274(24):17267-17274.

17. Rios RM. The centrosome-Golgi apparatus nexus. Philos Trans $R$ Soc Lond B Biol Sci. 2014;369(1650):20130462.

18. Wei JH, Seemann J. Mitotic division of the mammalian Golgi apparatus. Semin Cell Dev Biol. 2009;20(7):810-816.

19. Müsch A. Microtubule organization and function in epithelial cells. Traffic. 2004;5(1):1-9.

20. Lu Z, Joseph D, Bugnard E, Zaal KJ, Ralston E. Golgi complex reorganization during muscle differentiation: visualization in living cells and mechanism. Mol Biol Cell. 2001;12(4):795-808.

21. Oddoux S, Zaal KJ, Tate V, et al. Microtubules that form the stationary lattice of muscle fibers are dynamic and nucleated at Golgi elements. J Cell Biol. 2013;203(2):205-213.

22. Ori-McKenney KM, Jan LY, Jan YN. Golgi outposts shape dendrite morphology by functioning as sites of acentrosomal microtubule nucleation in neurons. Neuron. 2012;76(5):921-930.

23. de Forges H, Bouissou A, Perez F. Interplay between microtubule dynamics and intracellular organization. Int J Biochem Cell Biol. 2012;44(2):266-274.

24. Egea G, Serra-Peinado C, Salcedo-Sicilia L, Gutiérrez-Martínez E. Actin acting at the Golgi. Histochem Cell Biol. 2013;140(3):347-360.

25. Papanikou E, Glick BS. Golgi compartmentation and identity. Curr Opin Cell Biol. 2014;29:74-81.

26. Gurel PS, Hatch AL, Higgs HN. Connecting the cytoskeleton to the endoplasmic reticulum and Golgi. Curr Biol. 2014;24(14): R660-R672.

27. Toivola DM, Tao GZ, Habtezion A, Liao J, Omary MB. Cellular integrity plus: organelle-related and protein-targeting functions of intermediate filaments. Trends Cell Biol. 2005;15(11):608-617.

28. Thyberg J, Moskalewski S. Role of microtubules in the organization of the Golgi complex. Exp Cell Res. 1999;246(2):263-279.

29. Cole NB, Sciaky N, Marotta A, Song J, Lippincott-Schwartz J. Golgi dispersal during microtubule disruption: regeneration of Golgi stacks at peripheral endoplasmic reticulum exit sites. Mol Biol Cell. 1996;7(4):631-650.

30. Zhu X, Kaverina I. Golgi as an MTOC: making microtubules for its own good. Histochem Cell Biol. 2013;140(3):361-367. 
31. Marsh BJ, Mastronarde DN, Buttle KF, Howell KE, McIntosh JR. Organellar relationships in the Golgi region of the pancreatic beta cell line, HIT-T15, visualized by high resolution electron tomography. Proc Natl Acad Sci U S A. 2001;98(5):2399-2406.

32. Presley JF, Cole NB, Schroer TA, Hirschberg K, Zaal KJ, LippincottSchwartz J. ER-to-Golgi transport visualized in living cells. Nature. 1997;389(6646):81-85.

33. Sciaky N, Presley J, Smith C, et al. Golgi tubule traffic and the effects of brefeldin A visualized in living cells. J Cell Biol. 1997;139(5): $1137-1155$.

34. Scales SJ, Pepperkok R, Kreis TE. Visualization of ER-to-Golgi transport in living cells reveals a sequential mode of action for COPII and COPI. Cell. 1997;90(6):1137-1148.

35. Mardones GA, Snyder CM, Howell KE. Cis-Golgi matrix proteins move directly to endoplasmic reticulum exit sites by association with tubules. Mol Biol Cell. 2006;17(1):525-538.

36. Trucco A, Polishchuk RS, Martella O, et al. Secretory traffic triggers the formation of tubular continuities across Golgi sub-compartments. Nat Cell Biol. 2004;6(11):1071-1081.

37. Tängemo C, Ronchi $\mathrm{P}$, Colombelli J, et al. A novel laser nanosurgery approach supports de novo Golgi biogenesis in mammalian cells. J Cell Sci. 2011;124(Pt 6):978-987.

38. Hook P, Vallee RB. The dynein family at a glance. J Cell Sci. 2006; 119(Pt 21):4369-4371.

39. Pavin N, Tolić-Nørrelykke IM. Dynein, microtubule and cargo: a ménage à trois. Biochem Soc Trans. 2013;41(6):1731-1735.

40. Corthésy-Theulaz I, Pauloin A, Pfeffer SR. Cytoplasmic dynein participates in the centrosomal localization of the Golgi complex. J Cell Biol. 1992;118(6):1333-1345.

41. Harada A, Takei Y, Kanai Y, Tanaka Y, Nonaka S, Hirokawa N. Golgi vesiculation and lysosome dispersion in cells lacking cytoplasmic dynein. J Cell Biol. 1998;141(1):51-59.

42. Stauber T, Simpson JC, Pepperkok R, Vernos I. A role for kinesin-2 in COPI-dependent recycling between the ER and the Golgi complex. Curr Biol. 2006;16(22):2245-2251.

43. Lippincott-Schwartz J, Cole NB, Marotta A, Conrad PA, Bloom GS. Kinesin is the motor for microtubule-mediated Golgi-to-ER membrane traffic. J Cell Biol. 1995;128(3):293-306.

44. Palmer KJ, Hughes H, Stephens DJ. Specificity of cytoplasmic dynein subunits in discrete membrane-trafficking steps. Mol Biol Cell. 2009;20(12):2885-2899.

45. Brown AK, Hunt SD, Stephens DJ. Opposing microtubule motors control motility, morphology and cargo segregation during ER-to-Golgi transport. Biol Open. 2014;3(5):307-313.

46. Caviston JP, Holzbaur EL. Microtubule motors at the intersection of trafficking and transport. Trends Cell Biol. 2006;16(10):530-537.

47. Fu MM, Holzbaur EL. Integrated regulation of motor-driven organelle transport by scaffolding proteins. Trends Cell Biol. 2014;24(10): 564-574.

48. Schroer TA. Dynactin. Annu Rev Cell Dev Biol. 2004;20:759-779.

49. Burkhardt JK, Echeverri CJ, Nilsson T, Vallee RB. Overexpression of the dynamitin (p50) subunit of the dynactin complex disrupts dyneindependent maintenance of membrane organelle distribution. J Cell Biol. 1997;139(2):469-484.

50. Quintyne NJ, Gill SR, Eckley DM, Crego CL, Compton DA, Schroer TA. Dynactin is required for microtubule anchoring at centrosomes. J Cell Biol. 1999;147(2):321-334.

51. Watson P, Forster R, Palmer KJ, Pepperkok R, Stephens DJ. Coupling of ER exit to microtubules through direct interaction of COPII with dynactin. Nat Cell Biol. 2005;7(1):48-55.

52. Deacon SW, Serpinskaya AS, Vaughan PS, et al. Dynactin is required for bidirectional organelle transport. J Cell Biol. 2003;160(3): 297-301.

53. Ross JL, Wallace K, Shuman H, Goldman YE, Holzbaur EL. Processive bidirectional motion of dynein-dynactin complexes in vitro. Nat Cell Biol. 2006;8(6):562-570.
54. Haghnia M, Cavalli V, Shah SB, et al. Dynactin is required for coordinated bidirectional motility, but not for dynein membrane attachment. Mol Biol Cell. 2007;18(6):2081-2089.

55. Berezuk MA, Schroer TA. Dynactin enhances the processivity of kinesin-2. Traffic. 2007;8(2):124-129.

56. Welte MA. Bidirectional transport along microtubules. Curr Biol. 2004;14(13):R525-R537.

57. Hoogenraad CC, Akhmanova A, Howell SA, et al. Mammalian Golgiassociated bicaudal-D2 functions in the dynein-dynactin pathway by interacting with these complexes. EMBO J. 2001;20(15):4041-4054.

58. Matanis T, Akhmanova A, Wulf $\mathrm{P}$, et al. Bicaudal-D regulates COPIindependent Golgi-ER transport by recruiting the dynein-dynactin motor complex. Nat Cell Biol. 2002;4(12):986-992.

59. Splinter D, Razafsky DS, Schlager MA, et al. BICD2, dynactin, and LIS1 cooperate in regulating dynein recruitment to cellular structures. Mol Biol Cell. 2012;23(21):4226-4241.

60. Young J, Stauber T, del Nery E, Vernos I, Pepperkok R, Nilsson T. Regulation of microtubule-dependent recycling at the trans-Golgi network by Rab6A and Rab6A'. Mol Biol Cell. 2005;16(1):162-177.

61. Grigoriev I, Splinter D, Keijzer N, et al. Rab6 regulates transport and targeting of exocytotic carriers. Dev Cell. 2007;13(2):305-314.

62. Saraste J, Goud B. Functional symmetry of endomembranes. Mol Biol Cell. 2007;18(4):1430-1436.

63. Yadav S, Puri S, Linstedt AD. A primary role for Golgi positioning in directed secretion, cell polarity, and wound healing. Mol Biol Cell. 2009;20(6):1728-1736.

64. Ríos RM, Sanchís A, Tassin AM, Fedriani C, Bornens M. GMAP-210 recruits gamma-tubulin complexes to cis-Golgi membranes and is required for Golgi ribbon formation. Cell. 2004;118(3):323-335.

65. Yadav S, Puthenveedu MA, Linstedt AD. Golgin160 recruits the dynein motor to position the Golgi apparatus. Dev Cell. 2012;23(1): 153-165.

66. Drin G, Morello V, Casella JF, Gounon P, Antonny B. Asymmetric tethering of flat and curved lipid membranes by a golgin. Science. 2008;320(5876):670-673.

67. Cardenas J, Rivero S, Goud B, Bornens M, Rios RM. Golgi localisation of GMAP210 requires two distinct cis-membrane binding mechanisms. BMC Biol. 2009;7:56.

68. Drin G, Casella JF, Gautier R, Boehmer T, Schwartz TU, Antonny B. A general amphipathic alpha-helical motif for sensing membrane curvature. Nat Struct Mol Biol. 2007;14(2):138-146.

69. Gillingham AK, Tong AH, Boone C, Munro S. The GTPase Arflp and the ER to Golgi cargo receptor Erv14p cooperate to recruit the golgin Rud3p to the cis-Golgi. J Cell Biol. 2004;167(2):281-292.

70. Bornens M. The centrosome in cells and organisms. Science. 2012; 335(6067):422-426.

71. Efimov A, Kharitonov A, Efimova N, et al. Asymmetric CLASPdependent nucleation of noncentrosomal microtubules at the trans-Golgi network. Dev Cell. 2007;12(6):917-930.

72. Chabin-Brion K, Marceiller J, Perez F, et al. The Golgi complex is a microtubule-organizing organelle. Mol Biol Cell. 2001;12(7): 2047-2060.

73. Malikov V, Cytrynbaum EN, Kashina A, Mogilner A, Rodionov V. Centering of a radial microtubule array by translocation along microtubules spontaneously nucleated in the cytoplasm. Nat Cell Biol. 2005; 7(12):1213-1218.

74. Rivero S, Cardenas J, Bornens M, Rios RM. Microtubule nucleation at the cis-side of the Golgi apparatus requires AKAP450 and GM130. EMBO J. 2009;28(8):1016-1028.

75. Takahashi M, Yamagiwa A, Nishimura T, Mukai H, Ono Y. Centrosomal proteins CG-NAP and kendrin provide microtubule nucleation sites by anchoring gamma-tubulin ring complex. Mol Biol Cell. 2002; 13(9):3235-3245.

76. Hurtado L, Caballero C, Gavilan MP, Cardenas J, Bornens M, Rios RM. Disconnecting the Golgi ribbon from the centrosome prevents directional cell migration and ciliogenesis. J Cell Biol. 2011;193(5):917-933. 
77. Wang Z, Wu T, Shi L, et al. Conserved motif of CDK5RAP2 mediates its localization to centrosomes and the Golgi complex. J Biol Chem. 2010;285(29):22658-22665.

78. Roubin R, Acquaviva C, Chevrier V, et al. Myomegalin is necessary for the formation of centrosomal and Golgi-derived microtubules. Biol Open. 2013;2(2):238-250.

79. Barr AR, Kilmartin JV, Gergely F. CDK5RAP2 functions in centrosome to spindle pole attachment and DNA damage response. J Cell Biol. 2010;189(1):23-39.

80. Wang Z, Zhang C, Qi RZ. A novel myomegalin isoform functions in Golgi microtubule organization and ER-Golgi transport. J Cell Sci. 2014;127(22):4904-4917.

81. Choi YK, Liu P, Sze SK, Dai C, Qi RZ. CDK5RAP2 stimulates microtubule nucleation by the gamma-tubulin ring complex. J Cell Biol. 2010;191(6):1089-1095.

82. Fong KW, Choi YK, Rattner JB, Qi RZ. CDK5RAP2 is a pericentriolar protein that functions in centrosomal attachment of the gamma-tubulin ring complex. Mol Biol Cell. 2008;19(1):115-125.

83. Verde I, Pahlke G, Salanova M, et al. Myomegalin is a novel protein of the Golgi/centrosome that interacts with a cyclic nucleotide phosphodiesterase. J Biol Chem. 2001;276(14):11189-11198.

84. Kim HS, Takahashi M, Matsuo K, Ono Y. Recruitment of CG-NAP to the Golgi apparatus through interaction with dynein-dynactin complex. Genes Cells. 2007;12(3):421-434.

85. Yan X, Habedanck R, Nigg EA. A complex of two centrosomal proteins, CAP350 and FOP, cooperates with EB1 in microtubule anchoring. Mol Biol Cell. 2006;17(2):634-644.

86. Hoppeler-Lebel A, Celati C, Bellett G, et al. Centrosomal CAP350 protein stabilises microtubules associated with the Golgi complex. J Cell Sci. 2007;120(Pt 18):3299-3308.

87. Moreno-Mateos MA, Espina AG, Torres B, et al. PTTG1/securin modulates microtubule nucleation and cell migration. Mol Biol Cell. 2011;22(22):4302-4311.

88. Maia AR, Zhu X, Miller P, Gu G, Maiato H, Kaverina I. Modulation of Golgi-associated microtubule nucleation throughout the cell cycle. Cytoskeleton (Hoboken). 2013;70(1):32-43.

89. Miller DD, Scordilis SP, Hepler PK. Identification and localization of three classes of myosins in pollen tubes of Lilium longiflorum and Nicotiana alata. J Cell Sci. 1995;108(Pt 7):2549-2563.

90. Miller PM, Folkmann AW, Maia AR, Efimova N, Efimov A, Kaverina I. Golgi-derived CLASP-dependent microtubules control Golgi organization and polarized trafficking in motile cells. Nat Cell Biol. 2009;11(9):1069-1080.

91. Millarte V, Farhan H. The Golgi in cell migration: regulation by signal transduction and its implications for cancer cell metastasis. Scientific World Journal. 2012;2012:498278.

92. Heimann K, Percival JM, Weinberger R, Gunning P, Stow JL. Specific isoforms of actin-binding proteins on distinct populations of Golgiderived vesicles. J Biol Chem. 1999;274(16):10743-10750.

93. di Campli A, Valderrama F, Babià T, De Matteis MA, Luini A, Egea G. Morphological changes in the Golgi complex correlate with actin cytoskeleton rearrangements. Cell Motil Cytoskeleton. 1999;43(4):334-348.

94. Lázaro-Diéguez F, Jiménez N, Barth H, et al. Actin filaments are involved in the maintenance of Golgi cisternae morphology and intraGolgi pH. Cell Motil Cytoskeleton. 2006;63(12):778-791.

95. Valderrama F, Babia T, Ayala I, Kok JW, Renau-Piqueras J, Egea G. Actin microfilaments are essential for the cytological positioning and morphology of the Golgi complex. Eur J Cell Biol. 1998;76(1):9-17.

96. Valderrama F, Durán JM, Babià T, Barth H, Renau-Piqueras J, Egea G. Actin microfilaments facilitate the retrograde transport from the Golgi complex to the endoplasmic reticulum in mammalian cells. Traffic. 2001;2(10):717-726.

97. Valderrama F, Luna A, Babià T, et al. The Golgi-associated COPIcoated buds and vesicles contain beta/gamma-actin. Proc Natl Acad Sci U S A. 2000;97(4):1560-1565.
98. Campellone KG, Webb NJ, Znameroski EA, Welch MD. WHAMM is an Arp2/3 complex activator that binds microtubules and functions in ER to Golgi transport. Cell. 2008;134(1):148-161.

99. Kirkbride KC, Hong NH, French CL, Clark ES, Jerome WG, Weaver AM. Regulation of late endosomal/lysosomal maturation and trafficking by cortactin affects Golgi morphology. Cytoskeleton (Hoboken). 2012;69(9):625-643.

100. Dippold HC, Ng MM, Farber-Katz SE, et al. GOLPH3 bridges phosphatidylinositol-4-phosphate and actomyosin to stretch and shape the Golgi to promote budding. Cell. 2009;139(2):337-351.

101. Ng MM, Dippold HC, Buschman MD, Noakes CJ, Field SJ. GOLPH3L antagonizes GOLPH3 to determine Golgi morphology. Mol Biol Cell. 2013;24(6):796-808.

102. Colón-Franco JM, Gomez TS, Billadeau DD. Dynamic remodeling of the actin cytoskeleton by FMNL1 $\gamma$ is required for structural maintenance of the Golgi complex. J Cell Sci. 2011;124(Pt 18): 3118-3126.

103. Ramabhadran V, Korobova F, Rahme GJ, Higgs HN. Splice variantspecific cellular function of the formin INF2 in maintenance of Golgi architecture. Mol Biol Cell. 2011;22(24):4822-4833.

104. Zilberman Y, Alieva NO, Miserey-Lenkei S, et al. Involvement of the Rho-mDial pathway in the regulation of Golgi complex architecture and dynamics. Mol Biol Cell. 2011;22(16):2900-2911.

105. Beck KA, Buchanan JA, Malhotra V, Nelson WJ. Golgi spectrin: identification of an erythroid beta-spectrin homolog associated with the Golgi complex. J Cell Biol. 1994;127(3):707-723.

106. Beck KA, Nelson WJ. A spectrin membrane skeleton of the Golgi complex. Biochim Biophys Acta. 1998;1404(1-2):153-160.

107. Holleran EA, Holzbaur EL. Speculating about spectrin: new insights into the Golgi-associated cytoskeleton. Trends Cell Biol. 1998; 8(1):26-29.

108. Godi A, Santone I, Pertile P, et al. ADP ribosylation factor regulates spectrin binding to the Golgi complex. Proc Natl Acad Sci U S A. 1998;95(15):8607-8612.

109. De Matteis MA, Morrow JS. Spectrin tethers and mesh in the biosynthetic pathway. J Cell Sci. 2000;113(Pt 13):2331-2343.

110. Salcedo-Sicilia L, Granell S, Jovic M, et al. $\beta$ III Spectrin regulates the structural integrity and the secretory protein transport of the Golgi complex. J Biol Chem. 2013;288(4):2157-2166.

111. Stankewich MC, Tse WT, Peters LL, et al. A widely expressed BIII spectrin associated with Golgi and cytoplasmic vesicles. Proc Natl Acad Sci US A. 1998;95(24):14158-14163.

112. Beck KA, Buchanan JA, Nelson WJ. Golgi membrane skeleton: identification, localization and oligomerization of a $195 \mathrm{kDa}$ ankyrin isoform associated with the Golgi complex. J Cell Sci. 1997; 110(Pt 10):1239-1249.

113. Devarajan P, Stabach PR, Mann AS, Ardito T, Kashgarian M, Morrow JS. Identification of a small cytoplasmic ankyrin (AnkG119) in the kidney and muscle that binds beta I sigma spectrin and associates with the Golgi apparatus. J Cell Biol. 1996;133(4):819-830.

114. Devarajan P, Stabach PR, De Matteis MA, Morrow JS. Na,KATPase transport from endoplasmic reticulum to Golgi requires the Golgi spectrin-ankyrin G119 skeleton in Madin Darby canine kidney cells. Proc Natl Acad Sci U S A. 1997;94(20): 10711-10716.

115. Kang Q, Wang T, Zhang H, Mohandas N, An X. A Golgi-associated protein 4.1B variant is required for assimilation of proteins in the membrane. J Cell Sci. 2009;122(Pt 8):1091-1099.

116. Holappa K, Suokas M, Soininen P, Kellokumpu S. Identification of the full-length AE2 (AE2a) isoform as the Golgi-associated anion exchanger in fibroblasts. J Histochem Cytochem. 2001; 49(2):259-269.

117. Holappa K, Munoz MT, Egea G, Kellokumpu S. The AE2 anion exchanger is necessary for the structural integrity of the Golgi apparatus in mammalian cells. FEBS Lett. 2004;564(1-2): 97-103. 
118. Percival JM, Hughes JA, Brown DL, et al. Targeting of a tropomyosin isoform to short microfilaments associated with the Golgi complex. Mol Biol Cell. 2004;15(1):268-280.

119. Siddhanta A, Radulescu A, Stankewich MC, Morrow JS, Shields D. Fragmentation of the Golgi apparatus. A role for beta III spectrin and synthesis of phosphatidylinositol 4,5-bisphosphate. J Biol Chem. 2003;278(3):1957-1965.

120. Holleran EA, Ligon LA, Tokito M, Stankewich MC, Morrow JS, Holzbaur EL. BIII Spectrin binds to the Arp1 subunit of dynactin. J Biol Chem. 2001;276(39):36598-36605.

121. Moriyama Y, Nelson N. H+-translocating ATPase in Golgi apparatus. Characterization as vacuolar H+-ATPase and its subunit structures. J Biol Chem. 1989;264(31):18445-18450.

122. Nakamura N, Tanaka S, Teko Y, Mitsui K, Kanazawa H. Four Na+/H+ exchanger isoforms are distributed to Golgi and post-Golgi compartments and are involved in organelle $\mathrm{pH}$ regulation. J Biol Chem. 2005;280(2):1561-1572.

123. Curwin AJ, von Blume J, Malhotra V. Cofilin-mediated sorting and export of specific cargo from the Golgi apparatus in yeast. Mol Biol Cell. 2012;23(12):2327-2338.

124. von Blume J, Duran JM, Forlanelli E, et al. Actin remodeling by ADF/ cofilin is required for cargo sorting at the trans-Golgi network. J Cell Biol. 2009; 187(7):1055-1069.

125. von Blume J, Alleaume AM, Cantero-Recasens G, et al. ADF/cofilin regulates secretory cargo sorting at the TGN via the Ca2+ ATPase SPCA1. Dev Cell. 2011;20(5):652-662.

126. Mazzochi C, Benos DJ, Smith PR. Interaction of epithelial ion channels with the actin-based cytoskeleton. Am J Physiol Renal Physiol. 2006;291(6):F1113-F1122.

127. Rodriguez-Boulan E, Kreitzer G, Müsch A. Organization of vesicular trafficking in epithelia. Nat Rev Mol Cell Biol. 2005;6(3):233-247.

128. Lázaro-Diéguez F, Colonna C, Cortegano M, Calvo M, Martínez SE, Egea G. Variable actin dynamics requirement for the exit of different cargo from the trans-Golgi network. FEBS Lett. 2007; 581(20):3875-3881.

129. Erickson JW, Zhang C, Kahn RA, Evans T, Cerione RA. Mammalian Cdc42 is a brefeldin A-sensitive component of the Golgi apparatus. $J$ Biol Chem. 1996;271(43):26850-26854.

130. Fucini RV, Navarrete A, Vadakkan C, et al. Activated ADP-ribosylation factor assembles distinct pools of actin on Golgi membranes. J Biol Chem. 2000;275(25):18824-18829.

131. Luna A, Matas OB, Martínez-Menárguez JA, et al. Regulation of protein transport from the Golgi complex to the endoplasmic reticulum by CDC42 and N-WASP. Mol Biol Cell. 2002;13(3):866-879.

132. Matas OB, Martínez-Menárguez JA, Egea G. Association of Cdc42/NWASP/Arp2/3 signaling pathway with Golgi membranes. Traffic. 2004;5(11):838-846.

133. Prigozhina NL, Waterman-Storer CM. Protein kinase D-mediated anterograde membrane trafficking is required for fibroblast motility. Curr Biol. 2004;14(2):88-98.

134. Wu WJ, Erickson JW, Lin R, Cerione RA. The gamma-subunit of the coatomer complex binds $\mathrm{Cdc} 42$ to mediate transformation. Nature. 2000;405(6788):800-804.

135. Harris KP, Tepass U. Cdc42 and vesicle trafficking in polarized cells. Traffic. 2010;11(10):1272-1279.

136. Hehnly H, Longhini KM, Chen JL, Stamnes M. Retrograde Shiga toxin trafficking is regulated by ARHGAP21 and Cdc42. Mol Biol Cell. 2009;20(20):4303-4312.

137. Chen JL, Fucini RV, Lacomis L, Erdjument-Bromage H, Tempst P, Stamnes M. Coatomer-bound $\mathrm{Cdc} 42$ regulates dynein recruitment to COPI vesicles. J Cell Biol. 2005;169(3):383-389.

138. Hehnly H, Stamnes M. Regulating cytoskeleton-based vesicle motility. FEBS Lett. 2007;581(11):2112-2118.

139. Cohen D, Müsch A, Rodriguez-Boulan E. Selective control of basolateral membrane protein polarity by Cdc42. Traffic. 2001;2(8): $556-564$.
140. Kroschewski R, Hall A, Mellman I. Cdc42 controls secretory and endocytic transport to the basolateral plasma membrane of MDCK cells. Nat Cell Biol. 1999;1(1):8-13.

141. Müsch A, Cohen D, Kreitzer G, Rodriguez-Boulan E. Cdc42 regulates the exit of apical and basolateral proteins from the trans-Golgi network. EMBO J. 2001;20(9):2171-2179.

142. Dubois T, Paleotti O, Mironov AA, et al. Golgi-localized GAP for Cdc42 functions downstream of ARF1 to control Arp2/3 complex and F-actin dynamics. Nat Cell Biol. 2005;7(4):353-364.

143. Estrada L, Caron E, Gorski JL. Fgd1, the Cdc42 guanine nucleotide exchange factor responsible for faciogenital dysplasia, is localized to the subcortical actin cytoskeleton and Golgi membrane. Hum $\mathrm{Mol}$ Genet. 2001;10(5):485-495.

144. Kostenko EV, Mahon GM, Cheng L, Whitehead IP. The Sec14 homology domain regulates the cellular distribution and transforming activity of the Rho-specific guanine nucleotide exchange factor Dbs. J Biol Chem. 2005;280(4):2807-2817.

145. Camera P, da Silva JS, Griffiths G, et al. Citron-N is a neuronal Rho-associated protein involved in Golgi organization through actin cytoskeleton regulation. Nat Cell Biol. 2003;5(12):1071-1078.

146. Gad AK, Nehru V, Ruusala A, Aspenström P. RhoD regulates cytoskeletal dynamics via the actin nucleation-promoting factor WASp homologue associated with actin Golgi membranes and microtubules. Mol Biol Cell. 2012;23(24):4807-4819.

147. Anitei M, Stange C, Parshina I, et al. Protein complexes containing CYFIP/Sra/PIR121 coordinate Arf1 and Rac1 signalling during clathrin-AP-1-coated carrier biogenesis at the TGN. Nat Cell Biol. 2010;12(4):330-340.

148. Rosso S, Bollati F, Bisbal M, et al. LIMK1 regulates Golgi dynamics, traffic of Golgi-derived vesicles, and process extension in primary cultured neurons. Mol Biol Cell. 2004;15(7):3433-3449.

149. Salvarezza SB, Deborde S, Schreiner R, et al. LIM kinase 1 and cofilin regulate actin filament population required for dynamin-dependent apical carrier fission from the trans-Golgi network. Mol Biol Cell. 2009;20(1):438-451.

150. Pathak R, Delorme-Walker VD, Howell MC, et al. The microtubule-associated Rho activating factor GEF-H1 interacts with exocyst complex to regulate vesicle traffic. Dev Cell. 2012;23(2): 397-411.

151. Mooren OL, Galletta BJ, Cooper JA. Roles for actin assembly in endocytosis. Annu Rev Biochem. 2012;81:661-686.

152. Carreno S, Engqvist-Goldstein AE, Zhang CX, McDonald KL, Drubin DG. Actin dynamics coupled to clathrin-coated vesicle formation at the trans-Golgi network. J Cell Biol. 2004;165(6):781-788.

153. Chen JL, Lacomis L, Erdjument-Bromage H, Tempst P, Stamnes M. Cytosol-derived proteins are sufficient for Arp2/3 recruitment and ARF/coatomer-dependent actin polymerization on Golgi membranes. FEBS Lett. 2004;566(1-3):281-286.

154. Kerkhoff E, Simpson JC, Leberfinger CB, et al. The Spir actin organizers are involved in vesicle transport processes. Curr Biol. 2001; 11(24):1963-1968.

155. Cao H, Weller S, Orth JD, et al. Actin and Arf1-dependent recruitment of a cortactin-dynamin complex to the Golgi regulates post-Golgi transport. Nat Cell Biol. 2005;7(5):483-492.

156. Kessels MM, Qualmann B. The syndapin protein family: linking membrane trafficking with the cytoskeleton. J Cell Sci. 2004;117(Pt 15): 3077-3086.

157. Praefcke GJ, McMahon HT. The dynamin superfamily: universal membrane tubulation and fission molecules? Nat Rev Mol Cell Biol. 2004;5(2):133-147.

158. Rozelle AL, Machesky LM, Yamamoto M, et al. Phosphatidylinositol 4,5-bisphosphate induces actin-based movement of raft-enriched vesicles through WASP-Arp2/3. Curr Biol. 2000;10(6):311-320.

159. Kessels MM, Dong J, Leibig W, Westermann P, Qualmann B. Complexes of syndapin II with dynamin II promote vesicle formation at the trans-Golgi network. J Cell Sci. 2006;119(Pt 8):1504-1516. 
160. Gomez TS, Billadeau DD. A FAM21-containing WASH complex regulates retromer-dependent sorting. Dev Cell. 2009;17(5):699-711.

161. Welch MD, Mullins RD. Cellular control of actin nucleation. Аnnu Rev Cell Dev Biol. 2002;18:247-288.

162. Heuvingh J, Franco M, Chavrier P, Sykes C. ARF1-mediated actin polymerization produces movement of artificial vesicles. Proc Natl Acad Sci U S A. 2007;104(43):16928-16933.

163. Merrifield CJ, Perrais D, Zenisek D. Coupling between clathrincoated-pit invagination, cortactin recruitment, and membrane scission observed in live cells. Cell. 2005;121(4):593-606.

164. Taylor MJ, Lampe M, Merrifield CJ. A feedback loop between dynamin and actin recruitment during clathrin-mediated endocytosis. PLoS Biol. 2012;10(4):e1001302.

165. Egea G, Lázaro-Diéguez F, Vilella M. Actin dynamics at the Golgi complex in mammalian cells. Curr Opin Cell Biol. 2006;18(2):168-178.

166. Almeida CG, Yamada A, Tenza D, Louvard D, Raposo G, Coudrier E. Myosin $1 \mathrm{~b}$ promotes the formation of post-Golgi carriers by regulating actin assembly and membrane remodelling at the trans-Golgi network. Nat Cell Biol. 2011;13(7):779-789.

167. Fath KR, Burgess DR. Golgi-derived vesicles from developing epithelial cells bind actin filaments and possess myosin-I as a cytoplasmically oriented peripheral membrane protein. J Cell Biol. 1993; 120(1):117-127.

168. Jacob R, Heine M, Alfalah M, Naim HY. Distinct cytoskeletal tracks direct individual vesicle populations to the apical membrane of epithelial cells. Curr Biol. 2003;13(7):607-612.

169. Montes de Oca G, Lezama RA, Mondragón R, Castillo AM, Meza I. Myosin I interactions with actin filaments and trans-Golgiderived vesicles in MDCK cell monolayers. Arch Med Res. 1997; 28(3):321-328.

170. Tyska MJ, Mackey AT, Huang JD, Copeland NG, Jenkins NA, Mooseker MS. Myosin-1a is critical for normal brush border structure and composition. Mol Biol Cell. 2005;16(5):2443-2457.

171. Coudrier E, Almeida CG. Myosin 1 controls membrane shape by coupling F-actin to membrane. Bioarchitecture. 2011;1(5):230-235.

172. Loubéry S, Coudrier E. Myosins in the secretory pathway: tethers or transporters? Cell Mol Life Sci. 2008;65(18):2790-2800.

173. Brandstaetter H, Kendrick-Jones J, Buss F. Myolc regulates lipid raft recycling to control cell spreading, migration and Salmonella invasion. J Cell Sci. 2012;125(Pt 8):1991-2003.

174. Fath KR. Characterization of myosin-II binding to Golgi stacks in vitro. Cell Motil Cytoskeleton. 2005;60(4):222-235.

175. DePina AS, Wollert T, Langford GM. Membrane associated nonmuscle myosin II functions as a motor for actin-based vesicle transport in clam oocyte extracts. Cell Motil Cytoskeleton. 2007;64(10):739-755.

176. Duran JM, Valderrama F, Castel S, et al. Myosin motors and not actin comets are mediators of the actin-based Golgi-to-endoplasmic reticulum protein transport. Mol Biol Cell. 2003;14(2):445-459.

177. Müsch A, Cohen D, Rodriguez-Boulan E. Myosin II is involved in the production of constitutive transport vesicles from the TGN. J Cell Biol. 1997;138(2):291-306.

178. Stow JL, Fath KR, Burgess DR. Budding roles for myosin II on the Golgi. Trends Cell Biol. 1998;8(4):138-141.

179. Miserey-Lenkei S, Chalancon G, Bardin S, Formstecher E, Goud B, Echard A. Rab and actomyosin-dependent fission of transport vesicles at the Golgi complex. Nat Cell Biol. 2010;12(7):645-654.

180. Storrie B, Micaroni M, Morgan GP, et al. Electron tomography reveals Rab6 is essential to the trafficking of trans-Golgi clathrin and COPIcoated vesicles and the maintenance of Golgi cisternal number. Traffic. 2012;13(5):727-744.

181. Wakana Y, van Galen J, Meissner F, et al. A new class of carriers that transport selective cargo from the trans Golgi network to the cell surface. EMBO J. 2012;31(20):3976-3990.

182. Lindsay AJ, Jollivet F, Horgan CP, et al. Identification and characterization of multiple novel Rab-myosin Va interactions. Mol Biol Cell. 2013;24(21):3420-3434.
183. Buss F, Spudich G, Kendrick-Jones J. Myosin VI: cellular functions and motor properties. Annu Rev Cell Dev Biol. 2004;20:649-676.

184. Warner CL, Stewart A, Luzio JP, et al. Loss of myosin VI reduces secretion and the size of the Golgi in fibroblasts from Snell's waltzer mice. EMBO J. 2003;22(3):569-579.

185. Sahlender DA, Roberts RC, Arden SD, et al. Optineurin links myosin VI to the Golgi complex and is involved in Golgi organization and exocytosis. J Cell Biol. 2005;169(2):285-295.

186. Jordens I, Marsman M, Kuijl C, Neefjes J. Rab proteins, connecting transport and vesicle fusion. Traffic. 2005;6(12):1070-1077.

187. Goud B, Gleeson PA. TGN golgins, Rabs and cytoskeleton: regulating the Golgi trafficking highways. Trends Cell Biol. 2010;20(6): 329-336.

188. Guzik-Lendrum S, Heissler SM, Billington N, et al. Mammalian myosin-18A, a highly divergent myosin. J Biol Chem. 2013;288(13): 9532-9548.

189. Farber-Katz SE, Dippold HC, Buschman MD, et al. DNA damage triggers Golgi dispersal via DNA-PK and GOLPH3. Cell. 2014; 156(3):413-427.

190. Bassereau P, Goud B. Physics, biology and the right chemistry. F1000 Biol Rep. 2011;3:7.

191. Guet D, Mandal K, Pinot M, et al. Mechanical role of actin dynamics in the rheology of the Golgi complex and in Golgi-associated trafficking events. Curr Biol. 2014;24(15):1700-1711.

192. Samaj J, Müller J, Beck M, Böhm N, Menzel D. Vesicular trafficking, cytoskeleton and signalling in root hairs and pollen tubes. Trends Plant Sci. 2006;11(12):594-600.

193. Akkerman M, Overdijk EJ, Schel JH, Emons AM, Ketelaar T. Golgi body motility in the plant cell cortex correlates with actin cytoskeleton organization. Plant Cell Physiol. 2011;52(10):1844-1855.

194. Shimmen T, Yokota E. Cytoplasmic streaming in plants. Curr Opin Cell Biol. 2004;16(1):68-72.

195. Boevink P, Oparka K, Santa Cruz S, Martin B, Betteridge A, Hawes C. Stacks on tracks: the plant Golgi apparatus traffics on an actin/ER network. Plant J. 1998;15(3):441-447.

196. Brandizzi F, Saint-Jore C, Moore I, Hawes C. The relationship between endomembranes and the plant cytoskeleton. Cell Biol Int. 2003;27(3):177-179.

197. Mollenhauer HH, Morre DJ. Cytochalasin B, but not colchicine, inhibits migration of secretory vesicles in root tips of maize. Protoplasma. 1976;87(1-3):39-48.

198. Satiat-Jeunemaitre B, Cole L, Bourett T, Howard R, Hawes C. Brefeldin A effects in plant and fungal cells: something new about vesicle trafficking? J Microsc. 1996;181(Pt 2):162-177.

199. Ito Y, Uemura T, Shoda K, Fujimoto M, Ueda T, Nakano A. cis-Golgi proteins accumulate near the ER exit sites and act as the scaffold for Golgi regeneration after brefeldin A treatment in tobacco BY-2 cells. Mol Biol Cell. 2012;23(16):3203-3214.

200. Chen Y, Chen T, Shen S, et al. Differential display proteomic analysis of Picea meyeri pollen germination and pollen-tube growth after inhibition of actin polymerization by latrunculin B. Plant $J$. 2006;47(2):174-195.

201. Yang YD, Elamawi R, Bubeck J, Pepperkok R, Ritzenthaler C, Robinson DG. Dynamics of COPII vesicles and the Golgi apparatus in cultured Nicotiana tabacum BY-2 cells provides evidence for transient association of Golgi stacks with endoplasmic reticulum exit sites. Plant Cell. 2005;17(5):1513-1531.

202. Saint-Jore CM, Evins J, Batoko H, Brandizzi F, Moore I, Hawes C. Redistribution of membrane proteins between the Golgi apparatus and endoplasmic reticulum in plants is reversible and not dependent on cytoskeletal networks. Plant J. 2002;29(5):661-678.

203. Picton JM, Steer MW. Determination of secretory vesicle production rates by dictyosomes in pollen tubes of Tradescantia using cytochalasin D. J Cell Sci. 1981;49:261-272.

204. Vidali L, McKenna ST, Hepler PK. Actin polymerization is essential for pollen tube growth. Mol Biol Cell. 2001;12(8):2534-2545. 
205. Blancaflor EB. The cytoskeleton and gravitropism in higher plants. J Plant Growth Regul. 2002;21(2):120-136.

206. Hu Y, Zhong R, Morrison WH 3rd, Ye ZH. The Arabidopsis RHD3 gene is required for cell wall biosynthesis and actin organization. Planta. 2003;217(6):912-921.

207. Nebenfuhr A, Gallagher LA, Dunahay TG, et al. Stop-and-go movements of plant Golgi stacks are mediated by the acto-myosin system. Plant Physiol. 1999;121(4):1127-1142.

208. Boutté Y, Vernhettes S, Satiat-Jeunemaitre B. Involvement of the cytoskeleton in the secretory pathway and plasma membrane organisation of higher plant cells. Cell Biol Int. 2007;31(7):649-654.

209. Kaksonen M, Toret CP, Drubin DG. Harnessing actin dynamics for clathrin-mediated endocytosis. Nat Rev Mol Cell Biol. 2006; 7(6):404-414.

210. Mulholland J, Wesp A, Riezman H, Botstein D. Yeast actin cytoskeleton mutants accumulate a new class of Golgi-derived secretary vesicle. Mol Biol Cell. 1997;8(8):1481-1499.

211. Adams AE, Pringle JR. Relationship of actin and tubulin distribution to bud growth in wild-type and morphogenetic-mutant Saccharomyces cerevisiae. J Cell Biol. 1984;98(3):934-945.

212. Kilmartin JV, Adams AE. Structural rearrangements of tubulin and actin during the cell cycle of the yeast Saccharomyces. J Cell Biol. 1984;98(3):922-933.

213. Moseley JB, Goode BL. The yeast actin cytoskeleton: from cellular function to biochemical mechanism. Microbiol Mol Biol Rev. 2006; 70(3):605-645.

214. Pruyne D, Legesse-Miller A, Gao L, Dong Y, Bretscher A. Mechanisms of polarized growth and organelle segregation in yeast. Annu Rev Cell Dev Biol. 2004;20:559-591.

215. Finger FP, Novick P. Synthetic interactions of the post-Golgi sec mutations of Saccharomyces cerevisiae. Genetics. 2000;156(3):943-951.

216. Spelbrink RG, Nothwehr SF. The yeast GRD20 gene is required for protein sorting in the trans-Golgi network/endosomal system and for polarization of the actin cytoskeleton. Mol Biol Cell. 1999;10(12):4263-4281.

217. Harsay E, Schekman R. Avl9p, a member of a novel protein superfamily, functions in the late secretory pathway. Mol Biol Cell. 2007;18(4):1203-1219.

218. Rossanese OW, Reinke CA, Bevis BJ, et al. A role for actin, Cdclp, and Myo2p in the inheritance of late Golgi elements in Saccharomyces cerevisiae. J Cell Biol. 2001;153(1):47-62.

219. Arai S, Noda Y, Kainuma S, Wada I, Yoda K. Ypt11 functions in bud-directed transport of the Golgi by linking Myo2 to the coatomer subunit Ret2. Curr Biol. 2008;18(13):987-991.

220. Santiago-Tirado FH, Legesse-Miller A, Schott D, Bretscher A. PI4P and Rab inputs collaborate in myosin-V-dependent transport of secretory compartments in yeast. Dev Cell. 2011;20(1):47-59.

221. Jin Y, Sultana A, Gandhi P, et al. Myosin V transports secretory vesicles via a Rab GTPase cascade and interaction with the exocyst complex. Dev Cell. 2011;21(6):1156-1170.

222. Brazer SC, Williams HP, Chappell TG, Cande WZ. A fission yeast kinesin affects Golgi membrane recycling. Yeast. 2000;16(2):149-166.

223. Jarmoszewicz K, Lukasiak K, Riezman H, Kaminska J. Rsp5 ubiquitin ligase is required for protein trafficking in Saccharomyces cerevisiae COPI mutants. PloS One. 2012;7(6):e39582.
224. Kaminska J, Spiess M, Stawiecka-Mirota M, et al. Yeast Rsp5 ubiquitin ligase affects the actin cytoskeleton in vivo and in vitro. Eur $J$ Cell Biol. 2011;90(12):1016-1028.

225. Kondylis V, Rabouille C. The Golgi apparatus: lessons from Drosophila. FEBS Lett. 2009;583(23):3827-3838.

226. Kondylis V, van Nispen tot Pannerden HE, Herpers B, Friggi-Grelin F, Rabouille C. The Golgi comprises a paired stack that is separated at G2 by modulation of the actin cytoskeleton through Abi and Scar/ WAVE. Dev Cell. 2007;12(6):901-915.

227. Papoulas O, Hays TS, Sisson JC. The golgin lava lamp mediates dynein-based Golgi movements during Drosophila cellularization. Nat Cell Biol. 2005;7(6):612-618.

228. Sisson JC, Field C, Ventura R, Royou A, Sullivan W. Lava lamp, a novel peripheral Golgi protein, is required for Drosophila melanogaster cellularization. J Cell Biol. 2000;151(4):905-918.

229. Bard F, Casano L, Mallabiabarrena A, et al. Functional genomics reveals genes involved in protein secretion and Golgi organization. Nature. 2006;439(7076):604-607.

230. Rybakin V, Clemen CS. Coronin proteins as multifunctional regulators of the cytoskeleton and membrane trafficking. Bioessays. 2005;27(6):625-632.

231. Becker B, Melkonian M. The secretory pathway of protists: spatial and functional organization and evolution. Microbiol Rev. 1996;60(4):697-721.

232. Jung E, Fucini P, Stewart M, Noegel AA, Schleicher M. Linking microfilaments to intracellular membranes: the actin-binding and vesicle-associated protein comitin exhibits a mannose-specific lectin activity. EMBO J. 1996;15(6):1238-1246.

233. Weiner OH, Murphy J, Griffiths G, Schleicher M, Noegel AA. The actin-binding protein comitin (p24) is a component of the Golgi apparatus. J Cell Biol. 1993;123(1):23-34.

234. Gloss A, Rivero F, Khaire N, et al. Villidin, a novel WD-repeat and villin-related protein from Dictyostelium, is associated with membranes and the cytoskeleton. Mol Biol Cell. 2003;14(7):2716-2727.

235. Rehberg M, Kleylein-Sohn J, Faix J, Ho TH, Schulz I, Gräf R. Dictyostelium LIS1 is a centrosomal protein required for microtubule/cell cortex interactions, nucleus/centrosome linkage, and actin dynamics. Mol Biol Cell. 2005;16(6):2759-2771.

236. Noratel EF, Petty CL, Kelsey JS, Cost HN, Basappa N, Blumberg DD. The adhesion modulation protein, AmpA localizes to an endocytic compartment and influences substrate adhesion, actin polymerization and endocytosis in vegetative Dictyostelium cells. BMC Cell Biol. 2012;13:29.

237. Eichinger L, Pachebat JA, Glöckner G, et al. The genome of the social amoeba Dictyostelium discoideum. Nature. 2005;435(7038):43-57.

238. Lee S, Han JW, Leeper L, Gruver JS, Chung CY. Regulation of the formation and trafficking of vesicles from Golgi by PCH family proteins during chemotaxis. Biochim Biophys Acta. 2009; 1793(7):1199-1209.

239. Somesh BP, Neffgen C, Iijima M, Devreotes P, Rivero F. Dictyostelium $\mathrm{RacH}$ regulates endocytic vesicular trafficking and is required for localization of vacuolin. Traffic. 2006;7(9):1194-1212.
Cell Health and Cytoskeleton

\section{Publish your work in this journal}

Cell Health and Cytoskeleton is an international, peer-reviewed open access journal focusing on all aspects of cell structure and function contributing to normal physiology and cell health and exploring the pathogenesis of cell dysfunction leading to adverse conditions and disease in the organism. The journal welcomes papers covering original research,

\section{Dovepress}

basic science, reviews and evaluations, guidelines, expert opinion and commentary, case reports and extended reports. The manuscript management system is completely online and includes a very quick and fair peerreview system, which is all easy to use. Visit http://www.dovepress.com/ testimonials.php to read real quotes from published authors. 